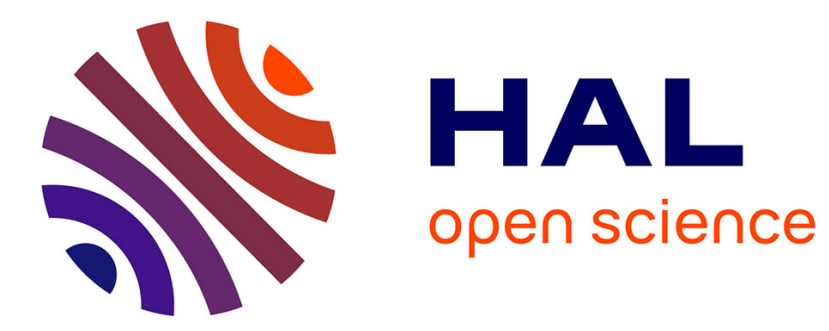

\title{
Relative Clauses in Tilapa Otomi
}

Enrique L Palancar

\section{To cite this version:}

Enrique L Palancar. Relative Clauses in Tilapa Otomi. Relative Clause Structure in Mesoamerican Languages, Brill, pp.252-290, 2021. hal-03503239

\section{HAL Id: hal-03503239 \\ https://hal.science/hal-03503239}

Submitted on 27 Dec 2021

HAL is a multi-disciplinary open access archive for the deposit and dissemination of scientific research documents, whether they are published or not. The documents may come from teaching and research institutions in France or abroad, or from public or private research centers.
L'archive ouverte pluridisciplinaire HAL, est destinée au dépôt et à la diffusion de documents scientifiques de niveau recherche, publiés ou non, émanant des établissements d'enseignement et de recherche français ou étrangers, des laboratoires publics ou privés. 


\title{
Relative Clauses in Tilapa Otomi
}

\author{
Enrique L. Palancar
}

\begin{abstract}
Tilapa Otomi (Oto-Manguean; Oto-Pamean; Otomian) has three types of relative clauses in headed relative constructions: (i) an asyndetic relative clause (i.e., a relative clause introduced by no subordinator); (ii) a RC introduced by a determiner that I argue works as a relativizer; and (iii) a relative clause introduced by a relative pronoun recruited from wH-words. Types (i) and (ii) use a gap relativization strategy, and they have a wide functional scope in the relativization hierarchy. Type (iii) only allows for WHO and WHERE in headed relative constructions, and these constructions are remarkable for two reasons. On the one hand, the locative relative pronoun strategy based on WHERE is the only construction that is available to relativize a locative adjunct. On the other hand, the relative clause based on WHO can only relativize a human subject and a human possessor, which is typologically surprising, although also found in Zenzontepec Chatino (see Campbell, this volume). All three types of relative clauses can be used as headless relative clauses with the addition of a fourth type involving a light head. In contrast to what happens in headed relative constructions, type (iii) involves a larger set of relative pronouns with a wider functional scope.
\end{abstract}




\title{
CHAPTER 8
}

\section{Relative Clauses in Tilapa Otomi}

\author{
Enrique L. Palancar
}

\subsection{Introduction}

In this chapter, I describe the relative clause (RC) syntax in Tilapa Otomi, an Otomian language of the Oto-Pamean branch of Oto-Manguean, which has recently become extinct in 2020 after the demise of its last fluent speaker, Mrs. Petra Cruz Gutiérrez-Mora. I propose that this language has three types of RCs that can be used in headed relative constructions: ${ }^{1}$ (i) an asyndetic RC (i.e., a RC introduced by no subordinator); (ii) a RC introduced by a determiner that I analyze as a relativizer; and (iii) a RC introduced by a relative pronoun recruited from WH-words. The two first types involve a gap as a relativization strategy and in headed relative constructions they are used to relativize a wide range of functions in the relativization hierarchy. In contrast, the relative pronoun strategy on which type (iii) is based can only employ WH-words for WHO and WHERE, and it is remarkable in two ways: first, the locative relative pronoun strategy based on WHERE is the only way in the language to relativize a locative adjunct; second, a RC based on WHO in relative constructions headed by a full nominal can only be used to relativize a human subject or a human possessor. This is typologically surprising, because there is an expectation that the restriction of such a construction should be based on the animacy feature of the domain nominal, not on its syntactic function; that is, one expects the relative pronoun strategy based on WHO to relativize subjects and objects alike. However, this is not what happens in Tilapa Otomi. Interestingly, the same situation is reported in Zenzontepec Chatino (see Campbell, this volume).

In the chapter, I further show how the three types of RCs are also used in headless relative constructions, with the addition of a fourth type involving a light head. In contrast to what happens in headed relative constructions, type (iii) involves a larger set of relative pronouns and has a wider functional scope.

To understand the syntax of RCs in Tilapa Otomi, there are a few things about the grammar of this language that have to be briefly introduced first, namely: (i) verbal inflection; (ii) nominal syntax, particularly with regard to type of determiners and their function; (iii) clausal word order; and (iv) a word about interrogatives given their relation to relative pronouns. I introduce this information in the following subsections. Following this, in Section 8.2, I introduce headed RCs and study in detail each of the three types of RCs mentioned above, finishing in Section 8.2.4 with their distribution in the relativization of different roles (based on the well-known hierarchy by Keenan \& Comrie 1977). In Section 8.3, I study headless RCs following the same schema, where I further introduce the light-headed type of RCs. Section 8.4 is a summary of the proposal.

\subsubsection{Basics of Verbal Inflection}

Verbs inflect for TAM values by means of inflectional markers that always precede the verbal stem, which I refer to as 'inflectional formatives'. Inflectional formatives may also convey notions of

\footnotetext{
${ }^{1}$ I use the concept of a relative construction as in Lehmann (1986).
} 
associated motion and voice, and they may even register the occurrence of adjuncts in focus in the clause (see Hernández-Green, 2016). Inflectional formatives also realize person of subject cumulatively for both transitive and active intransitive verbs (reference to a third person is indirect). ${ }^{2}$ I represent inflectional formatives as independent words to emphasize the periphrastic nature of Otomi inflection, but phonologically, they may be uttered as bound words when they are monosyllabic, like in (1). When they do so, they may procliticize to verb stems as in (1a), or encliticize to a previous word, especially in hesitative discourse, like in ( $1 b$ ) (indicated by $\approx$ ). We also have complex formatives, like in (1c), which consist of more than one syllable and they behave like more canonical phonological words. Both the formatives g $\underline{u}$ in (1a) and (1b) and giti in (1c) realize the same values (i.e., perfective irrealis for first person); they stand as allomorphs selected by the conjugation class of the verb. ${ }^{3}$
$g w \underline{u}=$
PFV.IRR.S1 Ss/go.PL.INCL $\approx \mathrm{P} \quad \mathrm{C}$.
'We go to Coatepec to sell.' $\{$ Txt $\}$
b. $\quad \boldsymbol{g} \underline{\boldsymbol{u}}=\quad m b a \quad \approx g \underline{u} . . \quad \quad g \underline{\boldsymbol{u}}=\quad{ }^{h} t s i=a$
PFV.IRR.S1 SS/go PFV.IRR.S1 PFV.IRR.S1 ingest $=\mathrm{CL}$
'I'll go to drink it.' (Lit. 'I'll go I'll... I'll drink it.') $\{$ Txt $\}$
(1) a. $\boldsymbol{g} \underline{u}=$
$m b \underline{a} \approx \prime a$
T'okk'eñö
c. giti nëx='be=a $t a=\quad m b a$
PFV.IRR.S1 set.on.course[O3].AS=PL.EXCL=CL PFV.IRR[S3 ss/go
'We'll set them on course so that they go.' $\{$ Txt $\}$

${ }^{h} p \underline{a}=h \underline{u}$

PFV.IRR.VEN.S1 $>$ EXLOC sell=PL.INCL

Table 8.1 shows the inflectional formatives of four basic (discourse frequent) TAM subparadigms of the transitive verb nde 'want'.

\footnotetext{
${ }^{2}$ In contrast to active intransitive verbs, inactive intransitive verbs inflect for person of subject by means of a set of person suffixes that is also used to index the object of transitive verbs. For this, compare (i) with (ii). A bare stem realizes third person, as in (i.b) or (ii.b). However, inactive verbs still use the same inflectional formatives to encode TAM. This is why information about a third person subject for both transitive and active intransitive verbs is realized (i.e., it is not part of the inherent meaning conveyed by the formative). In the examples, I only gloss reference to a third person object (or subject of an inactive intransitive) when it is anaphoric.

\begin{tabular}{|c|c|c|c|c|c|c|}
\hline & a. & $\begin{array}{l}b i \\
\mathrm{PFV}\end{array}$ & $\begin{array}{l}\text { hwötsi-gi } \\
\text { tremble.AS-S } S_{0} 1\end{array}$ & b. & $\begin{array}{l}b i \\
\mathrm{PFV}\end{array}$ & $\begin{array}{l}\text { hwöts'i } \\
\text { tremble }\left[\mathrm{s}_{03}\right]\end{array}$ \\
\hline & & 'I trembl & ed.' $\{\mathrm{Txt}\}$ & & 'S/he/th & mbled.' $\{\mathrm{Txt}\}$ \\
\hline ii. & a. & $\begin{array}{l}b i \\
\operatorname{PFv}\left[\mathrm{S}_{3}\right]\end{array}$ & $\begin{array}{l}\text { wön-gi } \\
\text { feed.AS-S } 1\end{array}$ & b. & $\begin{array}{l}b i \\
\operatorname{PFV}\left[\mathrm{s}_{3}\right]\end{array}$ & $\begin{array}{l}\text { wëni } \\
\text { feed[03] }\end{array}$ \\
\hline
\end{tabular}

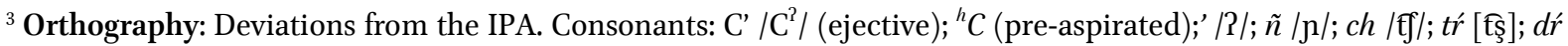
$[\cdot] ; n d y\left[\mathrm{n}_{\mathrm{f}}\right] ; r / \mathrm{r} / ; x / \mathrm{J} / ;$ and $y / \mathrm{j} /$. Vowels: $\underline{a} / \mathrm{J} /[\mathrm{p}] ; \underline{e} / \varepsilon / ; \underline{o} / 9 / ; \underline{u} / \mathrm{i} / ; \boldsymbol{e}[\mathrm{e}] ; \underline{o}[\mathrm{o}] ;$ and " nasal vowel. High tone is represented by an acute accent only in inflectional formatives. Abbreviations specific to this paper: $\approx$ indicates the encliticization of an element that in other circumstances could be a free word or a proclitic; $\$$ : female speaker; $\sigma^{\top}$ : male speaker.
} 
TABLE 8.1. Four TAM subparadigms of nde 'want' in Tilapa Otomi

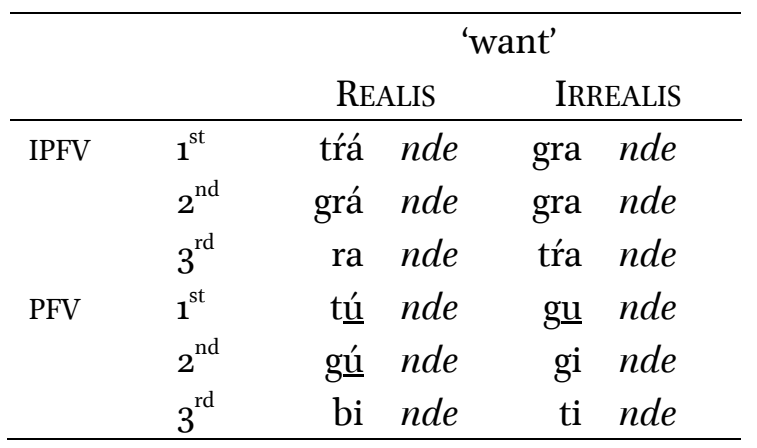

In the verbal phrase, a set of elements can precede inflectional formatives (in what I shall refer to as the 'preverbal zone'), such as adverbials (including negation adverbs) and indefinite pronouns. Examples are given in (2): (2a) illustrates the manner/reason adverbial khan; (2b) the conjunctive adverbial $x \underline{u}$ ' 'also'; and (2c) the negation marker hín and the degree adverbial =ts'e 'just'.
(2) a. khan $\approx d a ́$
mátú 'otu $=$ ='mbe $i$ txindi
MANN/RSN=PFV.ADV.S1 IMPF make.AS=PL.EXCL PL tamale
'We made tamale because of that.' $\{\mathrm{Txt}\}$

b. 'neh $\approx k a \quad x \underline{u} n \approx d$ ŕá he=tho mi pahni and.AS $\approx[\mathrm{SG}]_{\mathrm{PRO}}$ also=IPFV.S1 dress=DEL POSS19 shirt 'And I also put on my shirt.' $\{$ Txt $\}$

c. hin=ts' $\underline{\boldsymbol{e}}$ taga 'yo NEG=just PFV.IRR.ADLAT[S3] walk

'She no longer goes for a walk.' $\{$ Txt $\}$

\subsubsection{Basics of Nominal Syntax}

In Section 8.2.2, I show that in Tilapa Otomi there are RCs that are introduced by definite determiners. To understand their structure, I give an overview of nominal syntax here. In this respect, nouns can occur in bare NPs, like in (3), but more often than not they co-occur with a nominal classifier, like in $(4){ }^{4}$
(3) $t \underline{u}$
${ }^{h}$ tyü $\quad p \underline{o}$ 'kö
PFV.IRR.VEN[S3] bring manioc
'He'd bring manioc.' $\{\mathrm{Txt}\}$
(4) a. bi kha ar 're de $\mathrm{PFV}[\mathrm{S} 3]$ place CLF.SG ladder
'He placed the ladder.' $\{$ Txt $\}$

\footnotetext{
${ }^{4}$ Nominal classifiers always co-occur with nouns in Otomi (i.e., they cannot be used pronominally).
} 

b. tu ${ }^{h} t y \ddot{u} \quad i \quad z a$
PFV.IRR.VEN[S3] bring CLF.PL wood
'He'd bring firewood.' $\{$ Txt $\}$

While there is only one plural classifier for all nouns ( $i$ in $4 b),{ }^{5}$ there are at least three nominal classifiers for the singular. One is the general classifier ar in (4a). A second one is the classifier $r \underline{u}$, which occurs with a closed set of lexically specified nouns and with loanwords, like the noun $x \underline{e} b$ o 'animal grease' in ( 5 a) from Spanish sebo. The classifier $r \underline{u}$ also serves as the host for a floating tone that is a suprasegmental exponent of a third person possessive, like in $(5 \mathrm{~b}){ }^{6}{ }^{6}$ The third classifier is $r a$, which is used in verbal nominalizations, like in (6).

(5) a. pongi r $\underline{u} \quad x \underline{e} b o$

Q:much[s3] CLF.SG animal.grease

'It has a lot of grease.' $\{$ Txt $\}$

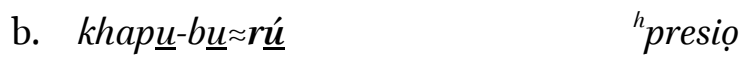

[IMP]put.AS-DAT3.AS $\approx$ CLF.SG.POSS3 price

'Put a price on it!'

(Lit. 'Put its price to it.') $\{$ Txt $\}$

(6) mádi $z i x-k \underline{u}=a \quad$ ra $\quad m b e n i$

IMPF.HAB[S3] ss/take.animate.AS-O1[SG].AS=CL CLF.NMLZ wash

'She used to take me to do the laundry.' $\{$ Txt $\}$

Nominal classifiers have no bearing on the encoding of definiteness. For definiteness, speakers can embed the NP in DPs headed by the definite article, either singular or plural, like in (7). There is also an indefinite article, illustrated in (8) with the singular.

(7) a. (pu)s kẹh=a a raso='ä

well $\mathrm{COP}\left[\mathrm{S}_{\mathrm{O}} 3\right] \cdot \mathrm{AS}=\mathrm{CL} \quad$ DEF.SG reason $=3 \mathrm{SG}_{\mathrm{PRO}}$

'Well, that's the truth.' $\{$ Txt $\}$

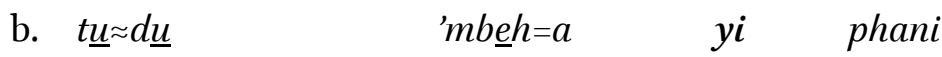

PFV.IRR.VEN $\approx$ INCH[S3] PASS/lose.AS=CL DEF.PL horse

'Horses are going to be extinct.' $\{$ Txt $\}$

(8) tú mïh=ka $\quad \boldsymbol{n}$ t'a t'egi

PFV.S1 grab.AS=1[SG $]_{\mathrm{PRO}}$ INDF.SG car

'I took a bus.' $\{$ Txt $\}$

Definite DPs are often headed by demonstratives, which are used as definite determiners, like in (9). The phrases in question may further include a possessed NP. A singular DP can be headed by

\footnotetext{
${ }^{5}$ Mass nouns are often used in the plural.

${ }^{6}$ In the plural, the element that may serve as a base for the suprasegmental can be the definite plural yi and the distal demonstrative plural $y \underline{u}$.
} 
the definite article and include demonstratives, like in (10a) and (1ob). In the plural, however, the inverse order is attested, as shown in (10c).

(9) a. bi 'yẹ ${ }^{j}=k^{\prime} e \quad$ ni kařo?

$\mathrm{PFV}[\mathrm{S} 3] \quad \mathrm{SS} /$ push.AS=2[SG $]_{\mathrm{PRO}}$ DEM.SG car

'Did the/that car run over you?' $\{\mathrm{Txt}\}$

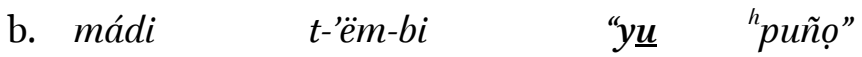

IMPF.HAB[S3] PASS-Say.AS-DAT3 DEM.PL fist

'He used to be called "the fists".' $\{$ Txt $\}$

(10) a. ru kháni a ni 'mbe $e^{j h} t s e$

CLF.SG.POSS3 person DEF.SG DEM.SG kid

'The people of the kid' $\{$ Txt $\}$

b. bw $\underline{u} \quad k h \underline{u}^{h} t i-g i \quad \boldsymbol{a} \quad \boldsymbol{n a} \quad m i \quad y \underline{e}=a$

PFV.VEN[S3] grab.DTR-DAT1[SG] DEF.SG DEM.SG POSS1 9 hand=CL

'They grabbed me by this hand.' $\{$ Txt $\}$

c. $x \underline{u} \quad$ 'mbox=a ki yi hme

$\mathrm{PRF}[\mathrm{S} 3] \quad$ IMPER/place.AS=CL DEM.PL DEF.PL tortilla

'They've placed the tortillas.' $\{$ Txt $\}$

Demonstratives can be used pronominally, like in (11a) where a demonstrative refers to the object. But there are also proper personal pronouns for third person, like in (11b). All proforms in Tilapa Otomi are enclitics; the full paradigm is given in Table 8.2.

(11) a. ta 'mboh=ni 'a hpatyo

PFV.IRR[S3] IMPER/throw.AS=DEM.SG ${ }_{\mathrm{PRO}} \quad \mathrm{P}$ courtyard

'They're going to throw it at the courtyard.' $\{$ Txt $\}$

b. $\quad r \underline{u} \quad k h \underline{a} \underline{u}^{\prime} i=\ddot{\boldsymbol{a}}$

IPFV.NOM.PRED[S3] person $=3 \mathrm{SG}_{\text {PRO }}$

'He's a man.' $\{$ Txt $\}$

TABLE 8.2. Pronominal enclitics in Tilapa Otomi

\begin{tabular}{|c|c|c|c|c|c|}
\hline & & SINGULAR & & DUAL & PLURAL \\
\hline \multirow{2}{*}{\multicolumn{2}{|c|}{$1^{\text {st }}$}} & \multirow{2}{*}{$=\mathrm{ga} / \mathrm{ka}$} & EXCL & - & $=\mathrm{ga} / \mathrm{ka}=$ 'mbe \\
\hline & & & INCL & $=g a / k a=w i$ & $=\mathrm{ga} / \mathrm{ka}=\mathrm{h} \underline{\mathrm{u}}$ \\
\hline $2^{\text {nd }}$ & & $=\mathrm{k}^{\prime} \mathrm{e}$ & & - & $=\mathrm{k}^{\prime} \mathrm{e}=\mathrm{wi}$ \\
\hline $3^{\text {rd }}$ & & ='a/'’ä & & - & $=\mathrm{k}^{\prime} \underline{\mathrm{u}}$ \\
\hline \multirow[t]{3}{*}{ DEM } & PROX & $=$ na & & - & $=y a$ \\
\hline & DISTAL I & $=\mathrm{ni}$ & & - & $=\mathrm{y} \underline{\mathrm{u}}$ \\
\hline & DISTAL II & $\left(=k^{\prime} a\right)$ & & - & $=\mathrm{k}^{\prime} \mathrm{i}$ \\
\hline
\end{tabular}




\subsubsection{Basics of Word Order}

To understand RC syntax in Tilapa Otomi it is important to appreciate certain aspects of word order because of two phenomena: (i) in Section 8.2.1, I show that RCs have a fixed word order; and (ii) there is a light-headed RC that I introduce in Section 8.3.4.1 that is only distinguishable from a canonical headed-RC by the position of the light head with respect to the RC.

First and foremost, Tilapa Otomi is a verb initial language, as can be seen in (12).
(12) vs
a. $\quad x \approx d$
’öxki
$[r \underline{u}$
$n k \ddot{u}]_{\mathrm{SUBJ}}$
already IPFV.ST be.nice[ $\left.\mathrm{S}_{0} 3\right]$ CLF.SG. POSS3 house
'Her house is very nice.' $\{$ Txt $\}$

vo
b. 'ne g $\underline{u}$
${ }^{h}$ pehti-k'i=wi
$\left[n t^{\prime} a\right.$
istoria $]_{\mathrm{OBJ}}$
and PFV.IRR.S1 tell.DTR-DAT2=PL INDF.SG tale
'And I'll tell you all a story.' $\{$ Txt $\}$

With two overt participant phrases, the order is VOS (the opposite word order to that reported for neighboring Acazulco Otomi by Hernández-Green, forthcoming). This is not only true of transitive clauses like (13), but also in intransitive clauses that exhibit the locative arguments of motion verbs, like in (14).
(13) mádikha hin $\approx a$
${ }^{h} p \ddot{o} \approx[r a$
syö $]_{\mathrm{OBJ}}[i$
$\left.k h \underline{a}^{\prime} i\right]_{\mathrm{SUBJ}}$
in.the.past $\mathrm{NEG} \approx \operatorname{IPFV}\left[\mathrm{S}_{3}\right]$ know.AS $\approx \mathrm{CLF} . \mathrm{NMLZ}$ word CLF.PL person
'In the past, people did not know how to speak.' $\{$ Txt $\}$ (Lit. '...know wording.')

(14)
a. ham $\approx b i$
'ëh=kwa
['a nikhö $]_{\mathrm{OBL}}[$ nterọ y $\underline{\mathrm{u}}$
sku 'mbe $e^{\text {jh }}$ tsẹ $]_{\text {SUBJ }}$ again $\approx \mathrm{PFV}[\mathrm{s}$
come.AS=her church
Q:all
DEM.PL
DIM kid
'All the kids came to church again.' $\{$ Txt $\}$

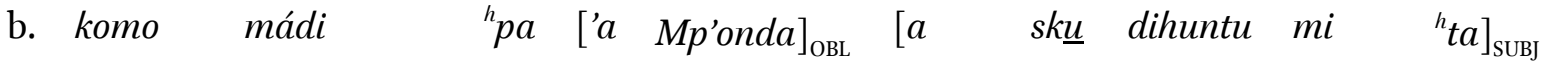 because IMPF.HAB $\left[\mathrm{s}_{3}\right]$ go $\mathrm{P}$ M. DEF.SG DIM late POSS19 father 'Because my father used to go to Mexico.' $\{$ Txt $\}$

Phrases can be fronted for information prominence, like in (15). In the context from where it was taken, the fronted DP in (15a) functioned as a contrastive topic; the PP in (15b) shows a location in focus.

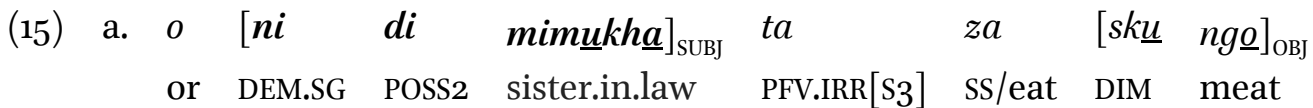
'Or your sister-in-law is going to eat the meat.' $\{\mathrm{Txt}\}$

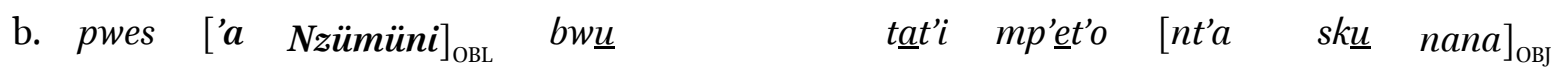
so $P$ T. PFV.VEN>EXLOC[S3] find firstly INDF.SG DIM woman 'It was in Toluca that they went and found a little girl.' 
The fronted DP in (15a) involves a possessed NP. When this is not the case, the fronted phrase is introduced by the presentational particle $\tilde{n} \ddot{u}$, like in (16).

\begin{tabular}{|c|c|c|c|c|c|c|}
\hline (16) kha & {$[\tilde{\boldsymbol{n}} \ddot{\boldsymbol{u}}=a$} & Lasaro $]_{\mathrm{SUBJ}}$ & $m a ́$ & 'mbw $\underline{u}$ & 'a & lagloria \\
\hline and.then & PRTCL=DEF.SG & $\mathrm{L}$. & $\operatorname{IMPF}[\mathrm{s} 3]$ & live & $\mathrm{P}$ & heaven \\
\hline
\end{tabular}

With fronted pronouns, there are two possibilities. They either occur hosted by a fronted adverbial or a conjunction, in which case they are always topical, like in (17); or they form pronominal phrases based on the particle $\tilde{n} \ddot{u}$. When this happens, they are contrastive, either contrastive topic or contrastive focus. An example of contrastive focus is given in (18).

$\begin{array}{llll}\text { (17) 'ne } & x a=k^{\prime} \boldsymbol{e} & x i n \approx g r \underline{u} & \text { mula }=k^{\prime} e=a \text { ! } \\ \text { and then }=2[\mathrm{SG}]_{\mathrm{PRO}} & \text { also } \approx \text { IPFV.NOM.PRED.S2 } & \text { mule }=2[\mathrm{SG}]_{\mathrm{PRO}}=\mathrm{CL}\end{array}$

'And as for you, you are also a mule!' $\{$ Txt $\}$

(18) 'ne $\tilde{\text { nü }}=$ ga giti ndoya $=g a$

and $\quad$ PRTCL $=1[\mathrm{SG}]_{\mathrm{PRO}} \quad$ PFV.IRR.S2 call $[\mathrm{O} 3]=1[\mathrm{SG}]_{\mathrm{PRO}}$

'It's me who's going to call him.'

(Lit. 'I am going to call him.') \{Txt\}

Pronominal phrases like the one in (18) cannot occur post-verbally. This is shown by the ungrammaticality of (19). This is important, because as we will see in Section 8.3.4.1, light-headed RCs in Tilapa Otomi are introduced by pronouns based on $\tilde{n} \ddot{u}$, but in such constructions the pronouns can occur post-verbally, which is an indication that these structures are not mere instances of a relative construction headed by a pronoun.

$\begin{array}{llll}(19) * \quad \text { 'ne } & \text { giti } & \text { ndoya }(=g a) & \tilde{\boldsymbol{n}} \ddot{u}=\boldsymbol{g a} \\ \text { and } & \text { PFV.IRR.S2 } & \text { call }[\mathrm{O} 3]=1[\mathrm{SG}]_{\mathrm{PRO}} & \text { PRTCL=1 }[\mathrm{SG}]_{\mathrm{PRO}}\end{array}$

Intended reading: idem (18)

\subsubsection{Basics of Interrogative Syntax}

Interrogatives constitute another area of the grammar of Tilapa Otomi that has a direct impact on RC syntax, because relative pronouns in this language come from WH-words. The WH-words in $(20)$ ask for the identity of arguments based on a human $v s$. a non-human distinction, while the things being questioned in (21) are adjuncts.

(20) a. to $\approx b i \quad$ syoni- $k^{\prime} i=a$ ?

$\mathrm{WHO} \approx \mathrm{PFV}[\mathrm{S} 3] \quad$ SS/look.for.DTR[O3]-DAT2[SG]=CL

'Who looked for it for you?' $\{\mathrm{Txt}\}$

$\begin{array}{llll}\text { b. } & \text { te } & b w \underline{u} \approx t \underline{u} & ' n a-k^{\prime} \underline{u}=w i \text { ? } \\ & \text { WHAT } & \text { PFV.VEN[S3] INCH } & \text { give.to.1/2-S } 2 . \mathrm{AS}=\mathrm{PL}\end{array}$ 
'What were you given?' $\{$ Txt $\}$

(21) a. 'abwu kẹ gú phunts'i?

WHERE COP $\left[\mathrm{S}_{0} 3\right]$ PFV.S2 fall

'Where is it that you fell?' $\{\mathrm{Txt}\}$

b. kha mbwu ke ta

ta $\quad z \underline{o x} \approx a$

taldia?

FOC WHEN COP[S $\left.\mathrm{S}_{0} 3\right]$ PFV.IRR[S3] SS/arrive.here.AS $\approx$ DEF.SG

so.and.so.day

'When is it that that so-and-so day will arrive?' $\{$ Txt $\}$

Questions about manner, quantity or instrument involve a set of inflectional formatives from special subparadigms that I call 'adverbial inflection' (ADV), whose main function is to register the occurrence of an adjunct in focus (see Hernández-Green 2016 for more details). Examples are given in (22). As we will see in Section 8.2.4, adverbial inflection is also used to relativize instruments.

(22) a. 'a gata 's $\underline{\text { so'tu }}=g a$ ?

HOW PFV.RR.ADV.S1 arrive.there.AS=1[SG $]_{\mathrm{PRO}}$

'How am I going to get there?' $\{$ Txt $\}$

b. 'angu taga to opera $=g i=a$ ?

HOW.MUCH PFV.RR.ADV[S3] INCH operate.on $=\mathrm{S}_{0} 1[\mathrm{SG}]=\mathrm{CL}$

'How much is it going to cost to operate on me?'

(Lit. 'For how much am I going to be operated on?') \{Txt $\}$

c. te gata ${ }^{h}$ tsi+hme?

WHAT PFV.IRR.ADV.S1 ingest+tortilla

'With what am I going to eat (my tortillas)?' $\{$ Txt $\}$

Interrogative clauses can also be embedded as complements of matrix verbs. The examples in (23) illustrate two different uses of the same WH-word for WнAт: in (23a) the WH-word refers to an argument participant; and in (23b), with adverbial inflection, it encodes purpose.

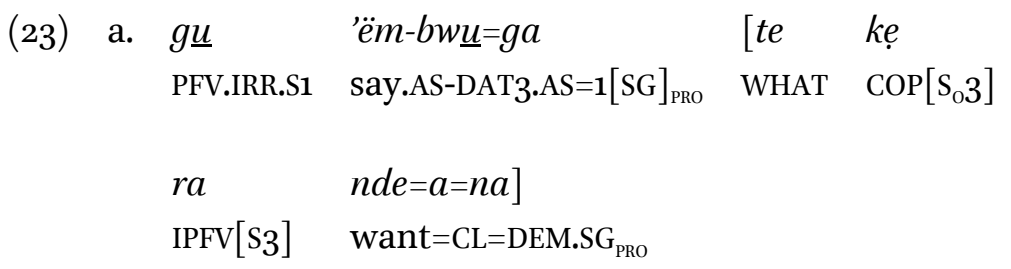

'I'm going to ask him what it is that he wants.' $\{$ Txt $\}$

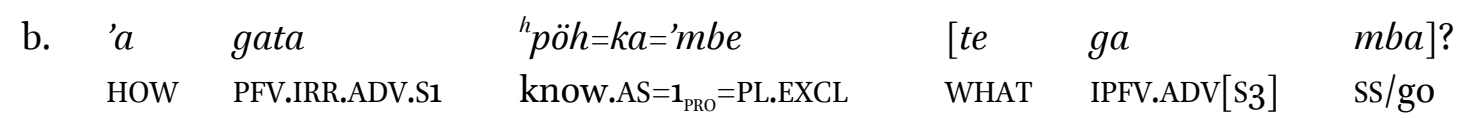
'How are we going to know what he's going after?' $\{$ Txt $\}$ 
Having seen some basics of the grammatical structure of Tilapa Otomi, in the following sections I concentrate on the syntax of RCs. In the next section, I present headed RCs. This will set up the general background that is necessary to understand the structure of headless RCs in Section 8.3, which are RCs that work as arguments or adjuncts of the matrix clause, and which have more intricate syntax.

\subsection{Headed Relative Clauses}

In this section, I introduce the three different types of headed RCs found in Tilapa Otomi: namely, (i) asyndetic RCs; (ii) RCs introduced by a determiner as a relativizer; and (iii) RCs introduced by a relative pronoun. All RCs, regardless of their type, have three properties in common: (i) they are finite clauses; (ii) they are postnominal; and (iii) they are externally headed.

\subsubsection{Asyndetic Headed Relative Clauses}

The most common type of headed RC in Tilapa Otomi is one that is asyndetic. In other words, it is NOT introduced by a linking element (i.e., it exhibits neither a complementizer nor a relative pronoun). This strategy appears to be characteristic of the Otomian branch of Oto-Pamean, because it is not only quintessential to Otomi (it has for example been reported in other Otomi languages, such as Acazulco Otomi by Hernández-Green, forthcoming; and in Northern Otomi by Palancar 2008), but it is also found in the Atzinca branch, such as in Matlatzinca (Palancar \& Carranza 2021).

An asyndetic RC has a gap (i.e., there is no overt manifestation of the head inside the RC) and it is used as a basic strategy (i.e., it can be, and is often, used to relativize a subject). Examples of headed asyndetic RCs are given in (24-27) and show the scope of functions that can be relativized: (24) illustrates relativized subjects, a human subject in (24a) and an inanimate in (24b); (25) involves the relativization of an object; (26) a temporal adjunct; and (27) a genitive phrase encoding the possessor. I indicate the function of the relativized element in small caps after the sign _ which indicates the gap.

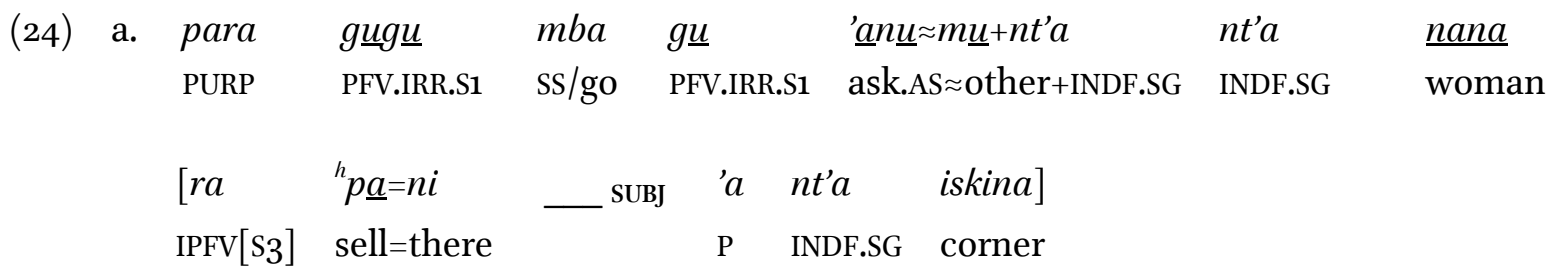

'So that I'll go and ask another woman who sells in one corner.' $\{$ Txt $\}$

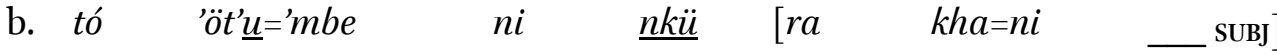
PFV.S1 paint.AS=PL.EXCL DEM.SG house IPFV[S3] exist=there
'We painted the house that is over there.' $\{$ Txt $\}$

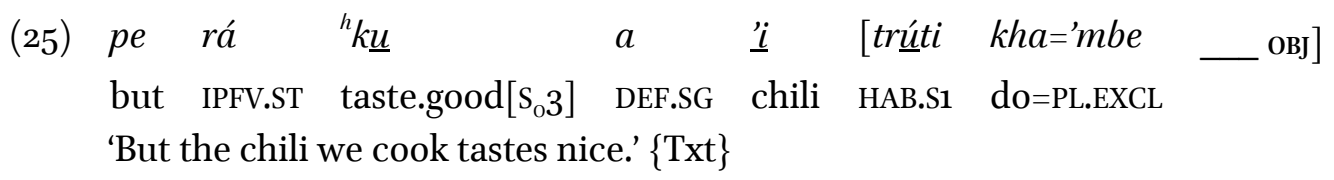

(26) bi zox $=a \quad$ a fetxa 
$\mathrm{PFV}\left[\mathrm{S}_{3}\right] \quad$ SS/arrive.there.AS=CL DEF.SG date

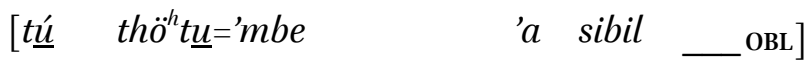

PFV.1 get.married.AS=PL.EXCL $\quad P \quad$ civil

'The date arrived that we got married at the civil registrar.' $\{$ Txt $\}$

(27) ton $\approx k e=a \quad$ ni $=a \quad \underline{\text { hani }}[$ [bi tyü

who.AS $\approx \mathrm{COP}\left[\mathrm{S}_{0} 3\right]=\mathrm{CL} \quad$ DEM.SG man $\quad \mathrm{PFV}\left[\mathrm{S}_{3}\right] \quad$ SS/die

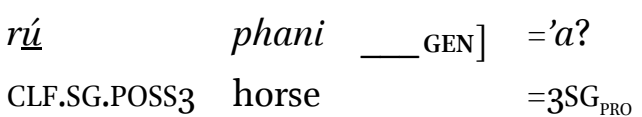

'Who is the man whose horse died?' (Elic.)

The fact that a RC of this type has no linker to introduce it as a subordinate clause makes its interpretation as a subordinate clause more dependent on its prosodic structure. To achieve the right interpretation, the string that constitutes the clause needs to be uttered within the same intonational unit as the NP containing its head. This is particularly obvious when the NP in question is fronted before the verb, as shown in example (28). The utterance in (28) is given in the spectrogram in Figure 8.1, which shows that both the fronted NP and its RC form one intonational unit. The complex fronted constituent formed by the DP and the restricted RC is then separated from the string encoding the VP by a slight pause; that intonational unit in turn forms part of the larger intonational contour of the matrix clause.

(28) $n i \approx r$

$\underline{\text { khani }}$ [má 'ëhë] ba tyü $\quad i$

tŕindi

DEM=CLF.SG man IMPF[s3] come PFV.VEN[s3] ss/bring CLF.PL tamale

'The man who came brought tamales.' (Elic.)

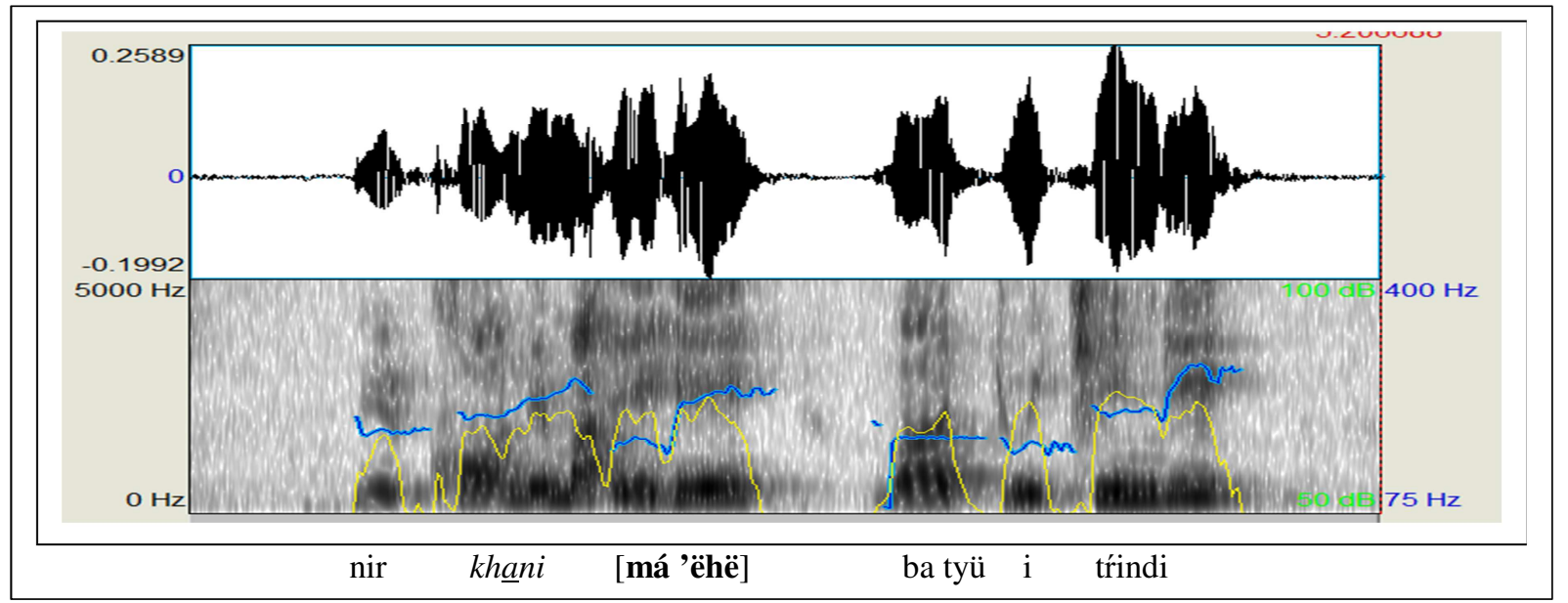

FIGURE 8.1. The prosody of the asyndetic headed RC in (28)

\footnotetext{
${ }^{7}$ Example (28) is elicited from Spanish and it mimics the SVO order of Spanish. It is not a natural rendition in Tilapa Otomi, and it does not even exhibit the presentational particle $\tilde{n} \ddot{u}$, but it is the best one that I have in my data to show the prosodic dependence of an asyndetic RC on its head.
} 
The fact that the RC and its head must always occur in the same prosodic unit is also a sign of the syntactic integration of the RC. When there is a pause between the head and its RC, the interpretation of the RC as a subordinate clause is broken, resulting in a chain of paratactic clauses. This is shown by the contrast between (29a) and (29b). If speakers pause at any point, the only option available to them is to pause after the inflectional formative of the predicate in the $\mathrm{RC}$, which is then hosted as an enclitic on the head. The enclitic may or may not be repeated in the RC. This is shown in (29c), which is the actual attested example of (29a). In the examples, the sign \# indicates a pause, and as described in Note 3 , the sign $\approx$ indicates the encliticization of an element that does not belong to the syntactic phrase of the phonological host.

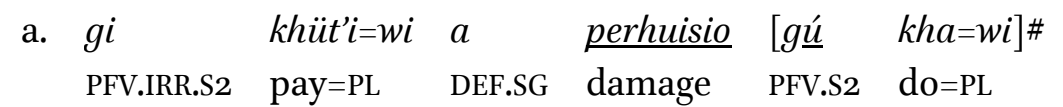

'You'll pay for the damage you've made.'
b. gi khüt'i=wi a perhuisio \# $[g \underline{u} \quad k h a=w i] \#$
PFV.IRR.S2 pay=PL DEF.SG damage PFV.S2 do[03]=PL
'You'll pay for the damage, (because) you've made it.'
(Infelicitous for the reading in 29a)

$$
\begin{array}{llllll}
\text { c. } & g i & k h \ddot{u} t^{\prime} i=w i & a & \text { perhuisio } \approx\left[\begin{array}{lll}
g \underline{u} \# & g \underline{u} & k h a=w i
\end{array}\right] \\
\text { PFV.IRR.S2 } & \text { pay=PL } & \text { DEF.SG } & \text { damage } \approx \text { PFV.S2 } & \text { PFV.S2 } & \text { do=PL } \\
\text { 'You'll pay for the damage you've...you've made.' }\{\text { Txt }\} &
\end{array}
$$

Asyndetic RCs are well known in the literature, mainly because English allows for them with a relativized object, as in the man [I saw _OBJ] or in the translations of (29). Such structures are called 'contact relatives', and they always allow for equivalent structures with the complementizer that, as in the man [that I saw_OBJ]. ${ }^{8}$ The same behavior is shown in complement clauses that function as objects of the matrix, as in I saw [that he came], which is equal to I saw [he came]. This has triggered the idea that all such structures have the same syntax, and that the asyndetic examples exhibit a phonologically silent or a zero complementizer. In turn, this means that in the analysis, when there is no linker one should theoretically assume that there is still one, because the generative model assumes that all languages have the same arborescent syntactic structure and that all of them have complement phrases. While this may be true for English, which always has the option of having an overt complementizer, it is not entirely clear what benefits assuming the same analysis for the syntax of languages like Tilapa Otomi would bring to the description. In any case, the language has no overt complementizers in other domains when they are typologically expected, such as in purpose or complement clauses, like the examples in (30) and (31), respectively, which also exhibit asyndetic subordinate clauses. In light of these examples, the use of asyndesis in RCs can be interpreted as a manifestation of the natural syntactic option for subordination in the language.

\footnotetext{
${ }^{8}$ Quirk et al. (1985: 1252) point out that contact relatives abound in more informal discourse, and that they are preferred when the syntactic string of the head is not complex and when "the relative clause itself [is] fairly short and simple".
} 
(30) 'ne gw $\underline{u} \quad{ }^{h} p e h n \underline{u}=g \underline{u}=' m b e \quad\left[\begin{array}{ll}t a & \left.x \underline{o}^{w} t s^{\prime} i\right]\end{array}\right.$

and PFV.IRR.VEN>EXLOC.S1 send[O3].AS=1[SG $]_{\mathrm{PRO}}$.AS=PL.EXCL PFV.IRR[S3] lift[O3]

'And we're going to send him there so that he can lift it (the wall) up.' $\{\mathrm{Txt}\}$

(31) 'ne tú $\quad \tilde{n} \ddot{u}=a \quad[p a \quad$ 'ë='ku]

and PFV.S1 see $=\mathrm{CL}$ PFV.VEN[S3] come.AS=there

'And I saw that she came from over there.' $\{\mathrm{Txt}\}$

Another syntactic property of asyndetic RC, which could be extended to all types, is that the order of constituents has to be predicate initial. This restriction suggests that this type of subordinated clause does not allow for any syntactic projections to the left of the predicate. This can be seen by comparing (32a) with the ungrammaticality of $(32 b) .^{9}$

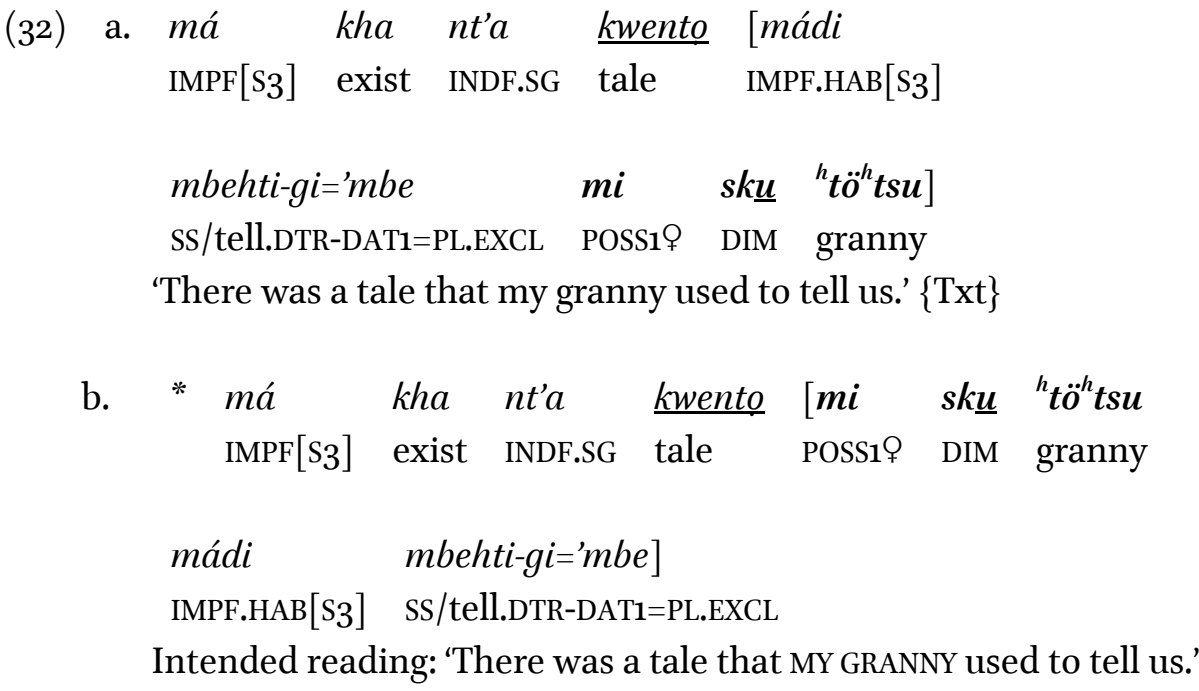

But it should be clear that it is not the verb that occurs in initial position, but the predicate phrase and, as such, it can involve elements of the preverbal zone, such as negation and other elements, as exemplified in (33).

(33) $b a$

$\begin{array}{lllll}b a & \dddot{e} h \approx p a & {[\text { hin=ts'e }} & \text { taga } & k \text { ka } \\ \text { IPFV.VEN[S3] } & \text { come.AS } \approx \text { day } & \text { NEG=just } & \text { PFV.IRR.ADV[S3] } & \text { exist }\end{array}$

ya $\quad y \underline{u} \approx s k \underline{u} \quad$ the $\underline{\underline{u}} w \ddot{o}=y a]$

DEM.PL DEF.PL.AS $\approx$ DIM fish $=$ CL

'The day's coming that these tiny fish will no longer exist.' $\{$ Txt $\}$

\subsubsection{Headed Relative Clauses Introduced by a Determiner as a Relativizer}

Another, although less common, type of RC in Tilapa Otomi is a RC introduced by a determiner. I follow Polian \& Aissen's (2021) proposal and analyze the determiner in such RCs as a complementizer. However, as this special complementizer is only used in RCs, I will treat it as a

\footnotetext{
${ }^{9}$ Objects are rarely fronted in matrix clauses, so there is no expectation to find fronted objects in a RC if subjects cannot be fronted.
} 
'relativizer'. This type of RC occurs in a relative construction where the head noun is embedded in a definite DP. This is illustrated in (34), an example of subject relativization that additionally shows that the construction uses a basic relativization strategy.

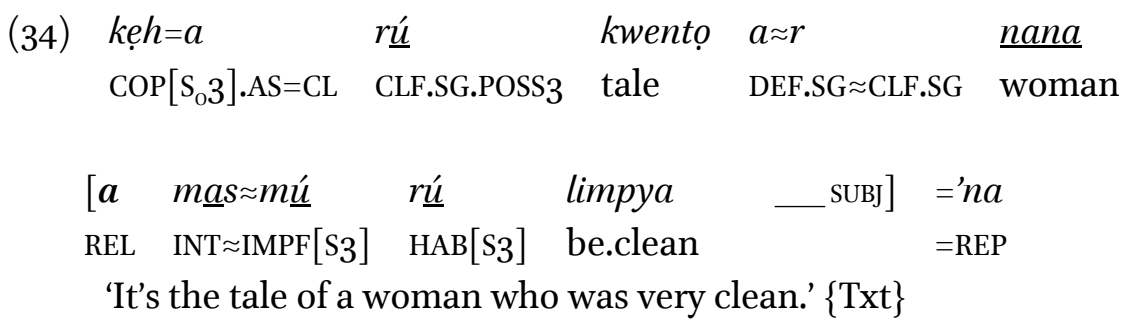

The Tilapa Otomi relative construction in (34) is similar to the construction reported for Tsotsil in Polian \& Aissen (2021) shown in (35). Here the proximal determiner li is used to introduce a headed RC every time the matrix NP is embedded in a DP headed by li. Aissen \& Polian (2021) analyze the determiner li in Tsotsil as a complementizer (hence the gloss COMP), but one that agrees in deixis with the matrix DP (hence the subscript DEIX).

TSOTSIL

(35) bat k-ak'-tikotik il-uk

go A1-give-1PL.EXCL see-SBJV

$\left.\begin{array}{lllllll}l i & j \text {-vun-tikotik } & {\left[l i_{i}\right.} & k o k^{\prime}-e m & \text { ta } & \text { Tuxta } & \text { un=e }\end{array}\right]$

'We went to show our papers that had been issued in Tuxtla.' $\{\mathrm{Txt}\}$

Polian \& Aissen (2021:411)

Note that an element like $l i$ in the RC in (35) is not analyzed as a relative pronoun, because deixis is not a feature of the head noun, but rather a property of the DP in which the noun is embedded. Hence the agreement is not with the noun, but with the determiner. A similar analysis could be postulated for Tilapa Otomi, and most probably for Acazulco Otomi, as described in HernándezGreen (forthcoming), where a similar construction is also found.

When there is more than one determiner in the DP embedding the domain nominal, the determiner introducing the RC agrees with the head of the DP, which is the first determiner to the right of the phrase. This can be seen in (36a), where we have two determiners (the definite singular $a$, and the demonstrative singular $n i$ ) and the agreement is with the definite determiner. Agreeing with the second one is ungrammatical, as shown in (36b).

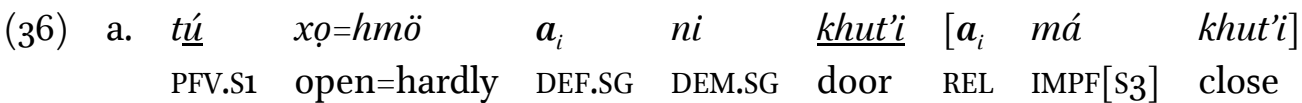
'I hardly opened the door that was closed.' $\{$ Txt $\}$

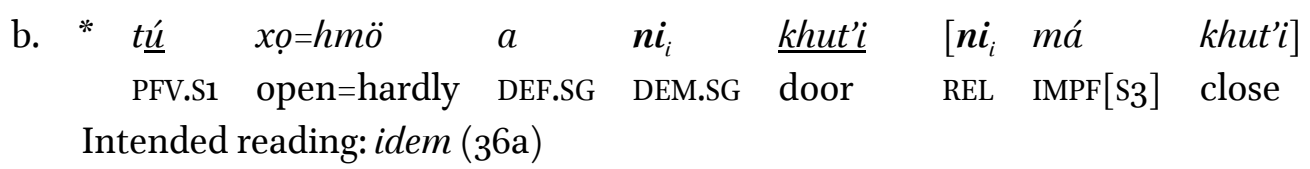


In cases where there is only one determiner, like in (37) or (38), this determiner is selected as the controller of agreement, regardless of whether it is a definite article as in (37) or a demonstrative (38). Examples like $\left(3^{6}-38\right)$ illustrate that it is not deixis controlling agreement, but rather the determiner head of the DP. The examples additionally illustrate that the scope of relativization of this construction goes beyond subject to include objects (in the case of (37), an indirect one) and genitive phrases, like in (38), which is an alternative to (27).

$\begin{array}{lllllllll}\text { (37) } & t \underline{u} & \tilde{n} \ddot{u}=g a & \boldsymbol{a}_{i} & \underline{k h a^{\prime} n i} & {\left[\boldsymbol{a}_{i}\right.} & g \underline{u} & { }^{h} p \underline{a} h-p y=a \approx r & \underline{\underline{o} n i}\end{array}$ 'I've seen the man to whom you sold the chicken.' (Elic.)

$$
\begin{aligned}
& \text { ton } \approx k e=a \quad n i_{i} \quad \underline{\text { khani }}\left[\begin{array}{lll}
n \boldsymbol{n i}_{i} & b i \quad \text { tyü }
\end{array}\right. \\
& \text { who.AS } \approx \mathrm{COP}\left[\mathrm{S}_{0} 3\right]=\mathrm{CL} \quad \text { DEM.SG man } \mathrm{REL} \quad \mathrm{PFV}[\mathrm{S} 3] \quad \text { SS/die } \\
& \text { rú phani _ GEN] ='a? } \\
& \text { PFV.SG.POSS3 horse } \quad=3 \mathrm{SG}_{\mathrm{PRO}}
\end{aligned}
$$

'Who is the man whose horse died?' (Elic.)

This RC structure cannot be used when the domain nominal is encoded in a NP (i.e., with no determiner), because there is no element to serve as a controller for the agreement, as shown by the ungrammaticality of (39).

$$
\begin{array}{lllll}
* \quad \text { 'nah- } \underline{u} \approx r & \underline{k h w a} & {[a} & g r i & \left.t a^{h} k \underline{u} \approx n g \underline{0}\right] \\
\text { [IMP]give.to.1/2.AS-1O.AS } \approx \text { CLF.SG } & \text { knife } & \text { REL } & \text { IPFV.ADV.S2 } & \text { cut.SS } \approx \text { meat }
\end{array}
$$

\subsubsection{Headed Relative Clauses Introduced by a Relative Pronoun}

Headed RCs can also be introduced by relative pronouns, which are recruited from WH-words. But in headed RCs, this only happens with two pronouns: the WH-word for humans to 'WHO', as in (4Oa), and the locative pronoun 'abw 'WHERE', in (4ob). In the next section, I elaborate on the scope of relativization of this strategy.

(40) a. 'ne trá 'ëm-bi $i \quad \underline{\text { hha'ni }}\left[\right.$ to $_{\mathrm{SUBJ}}$ má $\left.\quad x o x=a\right]$ and IPFV.S1 say.AS-DAT3 CLF.PL man WHO IMPF[S3] lift[O3].AS=CL 'And I tell the men who lifted it (the wall) up...' $\{$ Txt $\}$

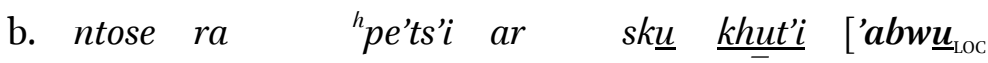
then IPFV[S3] have CLF.SG DIM door WHERE

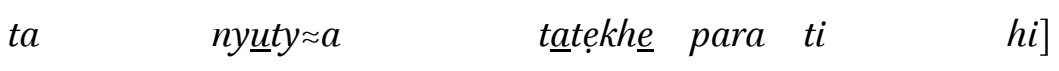
PFV.IRR[S3] SS/enter.AS $\approx$ DEF.SG patient PURP PFV.IRR[S3] bathe 'Then there's a small door where the patient goes through to have a bath.' $\{\mathrm{Txt}\}$ 


\subsubsection{Scope of Relativization of the Different Types of Relative Clauses}

In this section, I compare the scope of relativization of the three types of RCs that are used in headed relative constructions in Tilapa Otomi. A general overview is given in Table 8.3.

TABLE 8.3. Scope of relativization: $\checkmark$ attested in corpus; $[\checkmark$ elicitation;_not possible

\begin{tabular}{llccccccc}
\hline & & SUBJ & OBJ & INSTR & COM & GEN & TIME & LOC \\
\hline BASIC & GAP, ASYNDETIC & $\checkmark$ & $\checkmark$ & {$[\checkmark]$} & $\checkmark$ & $\checkmark$ & $\checkmark$ & - \\
& GAP, REL (DET) & $\checkmark$ & $\checkmark$ & $\checkmark$ & $\checkmark$ & $\checkmark$ & $\checkmark$ & - \\
& HUM.REL.PRO $t o$ & $\checkmark$ & - & - & $\checkmark$ & $\checkmark$ & - & - \\
SECONDARY & LOC.REL.PRO 'abwu & - & - & - & - & - & - & $\checkmark$ \\
\hline
\end{tabular}

As noted in Table 8.3, for the relativization of a location the syntax of Tilapa Otomi only allows for the relative pronoun strategy by means of a RC introduced by the locative relative pronoun 'abwu 'WHERE'. All other types of RCs regardless of strategy can serve as a basic strategy (i.e., strategies to relativize a subject). However, it should be noted that the RC introduced by the WH-word for humans to 'WHO' is only used for subjects and possessors (see further below about comitatives). In the light of what is common typologically, this is surprising because there is a latent expectation that if the relative pronoun strategy is available with a human domain nominal it should be used for the relativization of any core grammatical role involving a human. But this is not what happens in Tilapa Otomi, because while example (41a) is grammatical, example (41b) is ungrammatical. ${ }^{10}$

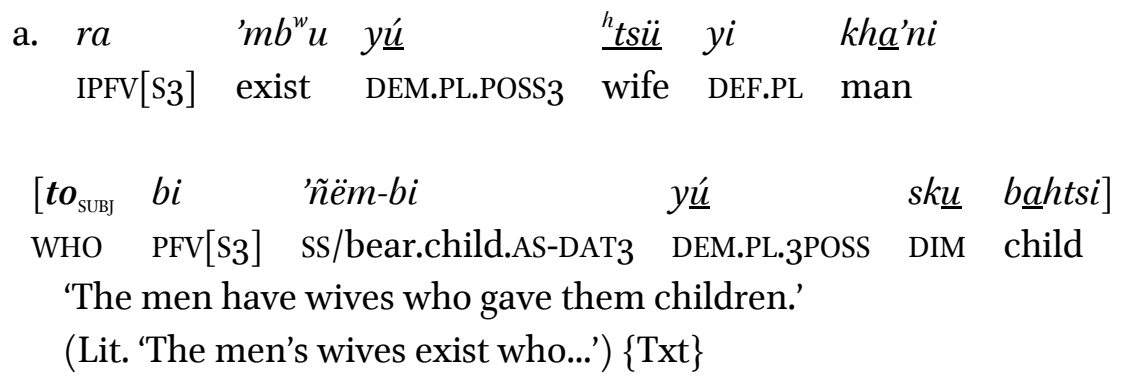

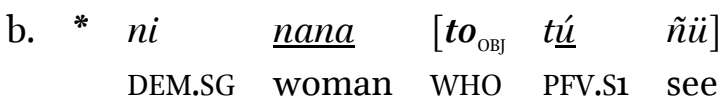
Intended reading: 'The woman that I saw.' (Elic.)

The restriction may be more widespread than previously thought, because Campbell (this volume) reports the same phenomenon for Zenzontepec Chatino, a language of the Zapotecan branch of Oto-Manguean that is too distant from Otomi to allow for an argument based on genetic proximity. Besides subject, the same construction can be used to relativize a comitative participant and the possessor in a genitive phrase.

The fact that objects are not accessible to relativization by the RC based on to 'WHO', but that comitatives are, could be taken to be a violation of Keenan \& Comrie's (1977) relativization hierarchy. In reality, it is not. The label 'COM' in Table 8.3 simply points to the semantic role of a

\footnotetext{
${ }^{10}$ The fact that the relative construction based on to 'WHO' is only accessible to relativize human subjects could be an indication that the construction is a recent development from the syntax of interrogatives.
} 
comitative participant, but says nothing about its grammatical encoding. In this connection, I have argued in Palancar (2012) that the comitative phrase in the comitative construction in Otomian languages functions as a second subject that controls subject agreement in number on the verb. The construction in question involves a conjunctional split, where the phrase encoding the subject and the phrase encoding the comitative are always discontinuous in the clause (i.e., they occur in different positions in the clause; and cannot be subsumed under the plural pronoun analysis in Schwartz 1985, 1988 or Aissen 1989). An example of the construction from Tilapa Otomi is given in (42), where the subject is a pronominal phrase in focus.
(42) kha $\left[\tilde{\boldsymbol{n}} \ddot{\boldsymbol{u}}=\boldsymbol{k}^{\prime} \boldsymbol{e}_{i}\right]_{\mathrm{SUBJ}} \quad$ giti thö $\ddot{o}^{h}=w i_{i+j}$ [ni mi and.then PRTCL $=2[\mathrm{SG}]_{\mathrm{PRO}}$ PFV.IRR.S2 get.married.AS=PL DEM.SG POSS1 9 daughter 'And YOU are going to marry my daughter?' $\{$ Txt $\}$

Any of the basic strategies in Table 8.3 can be used to relativize a comitative. Example (43a) presents an asyndetic RC, while (43b) shows an instance of a RC introduced by the WH-word to 'WHO'. The fact that the latter construction can be, and is often, used for this function is further evidence that the role of the comitative phrase in (42) or (43) is of a second subject (i.e., it is not an applicativized object).
a. $\tilde{n} \ddot{u}=a$
$\underline{\text { nana }}$
[bi thö $\ddot{c}^{h} t i=w i$ COM]
PRTCL=DEF.SG woman $\operatorname{PFV}[\mathrm{S} 3]$ get.married $=\mathrm{PL}$

$$
\begin{array}{ll}
b i & z \underline{u} h=a \\
\text { PFV[S3] } & \text { Ss/tell.off.AS[O3] }=\text { CL }
\end{array}
$$
'The woman whom he married told him off.'
(Lit. 'The woman with whom he married...') $\{$ Txt $\}$
b. pwes tú 'wë='mbe ni sk $\underline{u}$ nana
well PFV.S1 be.distant.AS=PL.EXCL DEM.SG DIM woman

$$
\begin{aligned}
& \text { [to } \text { to }_{\text {сом }} \text { tá ntx'o='mbe] } \\
& \text { WHO IPFV.VEN>EXLOC.S1 MIDDLE/walk=PL.EXCL }
\end{aligned}
$$

'Well, I've distanced myself from the woman with whom I used to go walking.'

A RC introduced by the WH-word to 'WHO' is also used for the relativization of a possessor, illustrated in the elicited examples in (44) (note that no natural examples were found in my text corpus)." In example (44a), the possessed phrase rú phani 'his horse' is left in situ; in (44b) it shows pied-piping with inversion (Smith-Stark, 1988). ${ }^{12}$

\footnotetext{
${ }^{11}$ The fact that this construction is also allowed for the relativization of a possessor is further evidence in favor of Lehmann's (1986) claim that the genitive phrase should be treated as a category which is independent of the relativization hierarchy.

${ }^{12}$ Pied-piping with inversion may also be used in the interrogation of a possessor, as in (i).

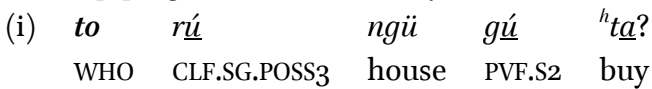
'Whose house did you buy?' (Elic.) 

(44) a. ni $\underline{\text { kha'ni}}\left[\begin{array}{lllll}\boldsymbol{t o}_{\mathrm{GEN}} & b i \quad \text { tyü } \underline{u} & \text { phani }\end{array}\right]$ DEM.SG man WHO PFV[S3] SS/die CFL.SG.3POSS horse 'The man whose horse died.' (Elic.)
b. ni $\underline{\text { hha'ni }}\left[\begin{array}{lllll}\boldsymbol{t o}_{\mathrm{GEN}} & \text { rú phani bi tyü] }\end{array}\right.$ DEM.SG man WHO CFL.SG.3POSS horse PFV[S3] ss/die idem (44a)

For the remaining relativizing functions, both RCs with the gap strategy (i.e., asyndetic RCs and RCs introduced by a determiner/relativizer) are in principle interchangeable, although all else being equal, asyndetic RCs are by far the most natural and common choice, with the exception of two situations, outlined below.

The first exception concerns the relativization of instruments for which a RC introduced by a determiner/relativizer is the preferred choice. While example (45a) shows that an asyndetic RC is possible, the options in $\left(45^{\mathrm{b}}\right)$ and $(45 \mathrm{c})$ are more natural. To relativize an instrument, the verb requires 'adverbial inflection' (see Section 8.1.4 above). In (45a), adverbial inflection involves the formative tagá for perfective irrealis instead of basic $t a$; in (45b) $g a$ is used for imperfective realis, instead of basic ra; and in (45c) the formative cluster támádi expresses imperfect realis of first person, instead of basic trámádi.
a. giti
PFV.IRR.S2 give.to.1/2-O1[SG].AS $\approx$ DEM.SG=CLF.SG knife
'nah-k $\underline{u} \approx n i=r$
$\underline{k h w a}$

\begin{tabular}{|c|c|}
\hline [tagá & tahki \\
\hline PFV.IRR.ADV[S3] & $\mathrm{ss} /$ cut $\left[\mathrm{S}_{3} \mathrm{O}\right]$ \\
\hline
\end{tabular}
'Give me the knife that she's going to cut it with.' (Elic.)

$\begin{array}{lllllll}\text { b. } & b i & \text { syóm-bi } & \boldsymbol{a}_{i} & \text { rú } & \text { sk } \underline{u} & \text { 'angaria } \\ & \text { PFV[S3] } & \text { SS/unload.AS-DAT3 } & \text { DEF.SG } & \text { CLF.SG.POSS3 } & \text { DIM } & \text { saddlebag }\end{array}$
$\left[\begin{array}{ll}a_{i} & g a\end{array}\right.$
ntyüx $\underline{u} \approx \dot{y} a$ INSTR]
REL IPFV.ADV[S3] TS/carry.AS $\approx$ fertilizer

'He unloaded it (the donkey) from the saddlebag that he was carrying the fertilizer in.' (Lit. '...with which he was carrying the fertilizer') \{Txt\}
c. 'neh $\approx k a \quad x i m \approx b i \quad g w a h=a \quad n i_{i}=r \quad \underline{k h w a}$ and.AS $\approx 1[\mathrm{SG}]_{\mathrm{PRO}} \quad$ also $\approx \mathrm{PFV}[\mathrm{S} 3] \quad$ SS/finish.AS=CL $\quad$ DEM.SG=CLF.SG knife

$\left.\begin{array}{lllll}{\left[\text { ni }_{i}\right.} & \text { támádi } & \text { tahki } & n i & \text { txühme _ INSTR }\end{array}\right]$

'And as for me, the knife that I used to cut the bread with has also broken.' (Elic.)

The second exception concerns the relativization of the subject of an inactive verb, for which only the asyndetic RC can be used (i.e., any other type of RC is ungrammatical). As most property 
concepts are encoded by means of stative verbs, which are a subclass of inactive verbs, the attribution of such concepts to a given entity is always carried out by means of an asyndetic RC, like in (46).

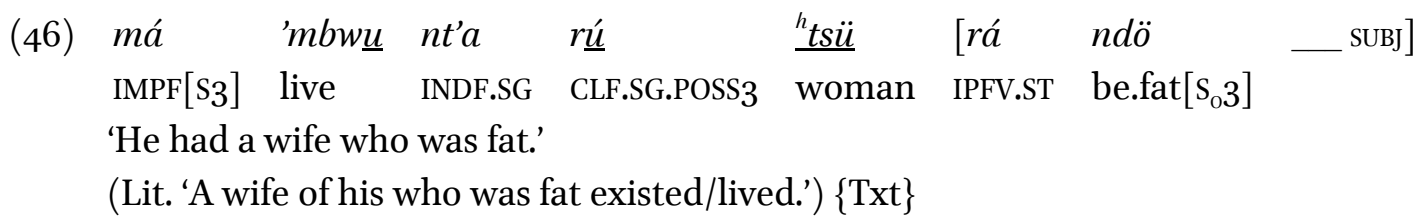

\subsection{Headless Relative Clauses}

Following Caponigro (2021), I take a headless RC to be a RC that is used as an argument or an adjunct of a given predicate in a clause. In Tilapa Otomi, there are various types of structures that serve this function. Three of them are clearly variations of the three types of RCs that we have seen in the headed constructions in the previous section. I introduce those first. Then I present another type of clause which is functionally equivalent to a headless RC, but which is headed by a pronominal that works as a light head. In the last subsection, I discuss the role of headless RCs in the formation of clefts in Tilapa Otomi, because clefts are a common structural environment where headless RCs abound in natural discourse.

\subsubsection{Asyndetic Headless Relative Clauses}

As well as in headed relative clauses (as we saw in Section 8.2.1), asyndetic RCs can also be used as headless RCs in Tilapa Otomi. This is shown in the examples in $\left(47-5^{\circ}\right)$. In (47) and (48), the RC functions as the subject of the matrix verb; in (49), it serves as the object (having been fronted before the verb); and in (50), it is the oblique stimulus of the emotion verb in the matrix clause.

(47) porke kha ti $z \underline{o}={ }^{\prime} k \underline{u}=w i$

because LOC.FOC PFV.IRR[S3] Ss/arrive.there.AS=there=DU

$\left[\right.$ nkhonts' $\underline{e} \quad y i \quad k h \underline{a}^{\prime} n i \quad$ GEN] ${ }^{\mathrm{G}} \mathrm{SUBJ}$

not.exist $\left[\mathrm{S}_{0} 3\right]$ DEF.PL.POSS3 person

'Because it's there where those who have no family end up.'

(Lit. '...(those whose) their family doesn't exist...') $\{$ Txt $\}$

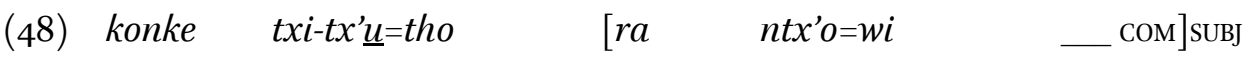
because DIM-little[ $\left.\mathrm{S}_{0} 3\right]=\mathrm{DEL} \quad \mathrm{IPFV}\left[\mathrm{S}_{3}\right] \quad$ MIDDLE/walk=DU

'Because it's just a little bit what she's got.'

(Lit. '...(what) she walks with...') $\{$ Txt $\}$

(49) $[x p i \quad$ etxaperder _ SUBJ]оBj tu $\quad$ 'uny $=a$

PRF go.off.food[s $\left.\mathrm{S}_{0} 3\right] \quad$ PFV.IRR.VEN $>$ EXLOC[S3] give[O3].AS=CL

'What had gone off (i.e., the gone-off food), he'd go and give to them.'

(Lit. '...(what) has gone off...') \{Txt $\}$ 


$\begin{array}{lllll}\text { porke } \quad t \underline{u} d \underline{u} & { }^{h} t s \ddot{u}=a & {[b i} & m b e^{h} t i-g i & \text { OBJ]OBL } \\ \text { because } & \text { PFV.S1 } & \text { get.scared=CL } & \text { PFV[S3] } & \text { Ss/tell.DTR-DAT1[SG] }\end{array}$
'Because I got scared of what he told me.'
(Lit. '...(what) he told me...') $\{$ Txt $\}$

The headless RCs in (47-50) all involve definite referents. The referents in question are the ones that have been relativized, for which there is a gap in the structure. The role of the referent within the RC can vary significantly. In (47), it is the possessor or the genitive phrase (i.e., 'the family of THOSE PEOPLE'); in (48), it is the comitative participant, which functions as a second subject in the RC (i.e., 'she walked (with) THAT THING'); in (49), it is the subject of the inactive predicate in the RC (i.e., 'THAT THING has gone off); and in (50), it is the object (i.e., 'he told me THAT THING').

All such headless RCs are semantically equivalent to maximal free relatives (see Section 8.3.3 below), but the structure can also be used to encode indefinite referents, like in (51), which has a comitative (i.e., 'I shall walk (with) SOMEBODY'). In contrast to all other examples, the headless RC in (52) just expresses a wish (i.e., 'WHATEVER God may allow me'), and it is thus an appositive structure not integrated into the syntax of the matrix clause.

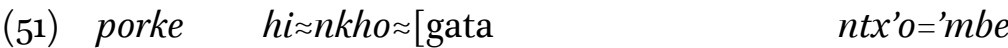
COM]SUBJ

because $\quad \mathrm{NEG} \approx$ not.exist[ $\left.\mathrm{S}_{0} 3\right]$.AS $\approx$ ADLAT.IRR.S1 MIDDLE1./walk=DU.EXCL

'Because I have nobody to go to (to ask for help).'

(Lit. 'Because there isn't (who) I shall go with.') \{Txt\}

(52) ntonses, [Khöndyọ rati 'yon-gu=tho _овJ],

then god IPFV[S3] allow.AS-O1[SG].AS=DEL

todabia trá... trá 'mbwu

still IPFV.S1 IPFV.S1 live

'Then, whatever (i.e., more years) God may allow me! I am still alive.'

(Lit. '...(what) God may allow me!...') \{Txt\}

\subsubsection{Headless Relative Clauses Introduced by a Determiner as a Relativizer}

The type of RC introduced by a determiner that I presented in Section 8.2.2 above can also be used as a definite headless RC. Whereas the choice of determiner in the headed relative construction is determined by agreement with the head of the DP embedding the domain nominal, when used as a headless RC the choice of determiner in the clause is triggered by the definiteness or the deixis semantics associated with the entity to which the clause makes reference. The construction is illustrated in examples (53-55). In (53), the RC is introduced by the definite singular determiner $a$, while in (54) and (55), the clauses are introduced by demonstratives: the proximal singular na 'this' and the distal plural y $\underline{u}$ 'those'. In examples (53) and (55), the RCs function as subject in the matrix clause, whereas in (54) the RC is the (secondary) object. In both (53) and (54), the syntactic role of the relativized element in the RC is that of object, whereas in (55) it is subject.
(53) hingu $\approx$ pongi
a giti 'nah-ki
NEG.AS $\approx$ be.a.lot $\left[\mathrm{S}_{0} 3\right] \quad$ REL 2.PFV.IRR give.to.1/2-O1[SG]
OBJ]SUBJ
'What you're going to give me is not much.' $\{\mathrm{Txt}\}$ 
$(54)$

$\begin{array}{lll}\text { Khöndyọ } & t i & \text { sokorre }=k^{\prime} e \\ \text { god } & \text { PFV.IRR }[\mathrm{S} 3] & \text { help.in.need }=2[\mathrm{SG}]_{\mathrm{PRO}}\end{array}$

[na gráti hwë-gi _ ОВJ]ОВJ

REL IPFV.S2 give.as.present.AS-O1[SG]

'May God help you with this that you're giving me!' $\{$ Txt $\}$

(55) porke ti $\quad m p^{\prime} \underline{u} h=a[\approx y \underline{u} \quad$...este... ni...

because PFV.IRR[S3] SS/live.AS=CL $\approx$ DEM.PL HES DEM.SG

$\begin{array}{llllll}y \underline{u} & t a & k h \underline{u} & r a \quad \text { sUBJ]SUBJ }\end{array}$

DEM.PL PFV.IRR[s3] grab CLF.NMLZ run

$\begin{array}{llll}\text { 'neh }=a \approx[y \underline{u} \approx t i . . . & t i & n \ddot{e} & \text { SUBJ]SUBJ } \\ \text { and }=\mathrm{CL}=\mathrm{DEM} . \mathrm{PL} \approx \mathrm{PFV} . \mathrm{IRR}[\mathrm{S} 3] & \text { PFV.IRR[S3] } & \text { dance }\end{array}$

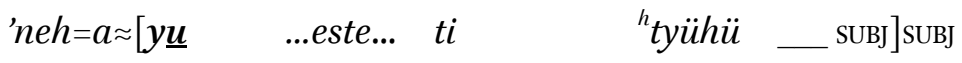

and $=\mathrm{CL}=$ DEM.PL HES PFV.IRR[S3] sow

'Because there's going to be those that... ehh... that one that... those that run, and those that sing, and those that... ehh... sow.' $\{\mathrm{Txt}\}$

\subsubsection{Free Relatives: Headless Relative Clauses Introduced by WH-Words}

Free RCs are headless RCs introduced by WH-words (Caponigro, 2003). We have seen in Section 8.2.3 that Tilapa Otomi also allows for the relative pronoun strategy in headed relative constructions, but there it can only involve the WH-word for humans to 'WHO' when the relativized element is subject (comitative or possessor), and the locative 'abw $\underline{u}$ 'WHERE' when it is a location. In contrast, when it comes to headless RCs, there are two key differences: (i) the WH-word for humans to 'WHO' can be used to relativize a greater number of elements; and (ii) a larger inventory of WH-words is possible.

The first of these differences is exemplified in (56) which shows instances of RCs introduced by the WH-word for humans to 'who'. In (56a), the RC clause is the subject of the matrix clause, while in (56b) and (56c), it is the object. Within the $\mathrm{RC}$, (56a) shows relativization of subject, whereas $(56 \mathrm{~b})$ and $(56 \mathrm{c})$ illustrate relativization of object and possessor, respectively. All examples have a definite referent.

(56) a. 'ne=a $\quad\left[\right.$ to $_{\text {SUBJ }}$ ti $\quad h i$ ' $\left.^{\prime} \underline{u}=a\right]$ SUBJ

and $=\mathrm{CL} \quad$ WHO PFV.IRR[S3] bathe-O2[SG].AS=CL

tra $\quad$ phe $\underline{b i-}{ }^{-} k \underline{u}=a$

IPFV.IRR[S3] beat.AS-O2[SG].AS=CL

'And [the one] who will bathe you, will be beating you.' $\{\mathrm{Txt}\}$

b. para hin $\approx d a . . \quad$ syegi $\left[\begin{array}{lll}\text { to... } & \text { to } & \\ \mathrm{OBJ} & \approx t a & \text { thandy }=a\end{array}\right.$

PURP NEG $\approx$ PFV.IRR[S3] SS/leave WHO WHO $\approx$ PFV.IRR[S3] tempt.AS=CL 


$$
\begin{array}{ll}
a & \text { hingi_ } \left.{ }^{h} t s \underline{a}\right] \text { ов } \\
\text { DEF.SG } & \text { devil }
\end{array}
$$

'So that they won't leave alone those...those whom the devil will tempt.' $\{$ Txt $\}$

$$
\begin{aligned}
& \text { c. } b i \quad z o h=a \quad\left[\begin{array}{lllll}
t_{\mathrm{GEN}} & b i \quad \text { tyü } \quad r \underline{u} & m b e
\end{array}\right] \mathrm{OBJ} \\
& \text { PFV[S3] Ss/talk.AS=CL WHO PFV[S3] ss/die CLF.SG.POSS3 mother }
\end{aligned}
$$

'He talked to the one whose mother had died.' $\{$ Txt $\}$

In terms of the inventory of WH-words that is possible with headless RCs in contrast to headed RCs, the headless relative construction can further involve the inanimate WH-word te 'WHAT'. Examples in (57) illustrate definite headless RCs which function as objects. Inside the RC, (57a) involves the relativization of subject, which in $(57 \mathrm{~b})$ it is the object that is relativized.
a. pe hin $\approx d e ́ \quad$ 'ëm-bi $\left[\boldsymbol{t e}_{\mathrm{SU \textrm {BJ }}}\right.$ rati $\left.{ }^{h} p a s a=g i\right]$ ов
but NEG $\approx$ PFV.S1 say.AS-DAT3 WHAT IPFV[S3] happen=O1[SG]
'But I didn't tell her what is happening to me.' $\{$ Txt $\}$
b. hin $\approx$ d'́úti ntiende='mbe
$\left[\begin{array}{lll}\boldsymbol{t} \boldsymbol{e}_{\mathrm{OBJ}} & \boldsymbol{r} \underline{u} & m \ddot{ }\end{array}\right]$ овЈ
$\mathrm{NEG} \approx \mathrm{HAB} . \mathrm{S} 1$ understand=PL.EXCL WHAT $\mathrm{HAB}[\mathrm{S} 3]$ say
'We don't understand what they say.' $\{$ Txt $\}$

All the above examples of headed RCs, including the asyndetic and the determiner/relativizer types, are used for arguments. For adjuncts, it is necessary to use free relatives. For a locative adjunct, we find the WH-word 'abw $\underline{u}$ 'WHERE', as in (58).

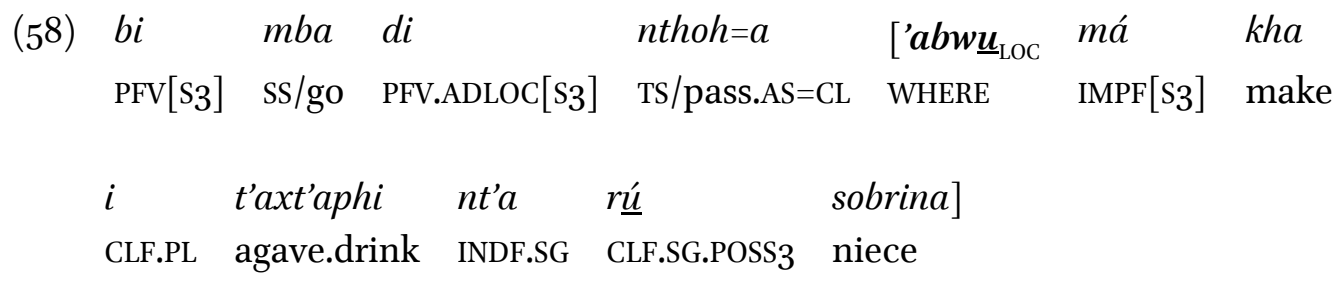

'He went and passed by the place where one of his nieces made agave drink.' $\{$ Txt $\}$

Free relatives can involve other WH-words. For example, temporal clauses introduced by $m b w \underline{u}$ 'WHEN' (59), or locative clauses introduced by the WH-word ' $a$ 'WHERE' (6o).
(59) $\quad\left[\boldsymbol{m b w} \underline{u}_{\mathrm{TIME}}\right.$ ta
'wö] hin=ts' $\underline{e}$ tigi
khu't'i
'When it rains, it will no longer be leaking away.' $\{$ Txt $\}$

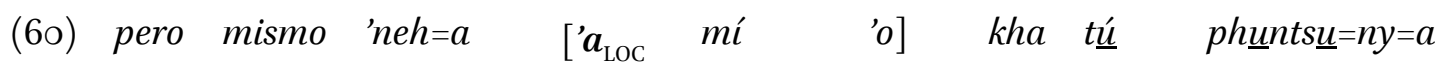
but right and.AS=CL WHERE IMPF[S3] sleep FOC PFV.S1 fall.AS=there=CL 'But where he was sleeping, it was right there where I fell down.' $\{$ Txt $\}$ 
In all Otomi languages there is a polysemy between locative and manner, in such a way that RCs bearing the locative relative pronoun ' $a$ 'WHERE' can also be used to express manner semantics. To achieve such a manner reading, the predicate in the RC is inflected with adverbial inflection. An example of a manner free relative is given in (61) (I indicate the polysemy as 'WHERE $>$ HOW').
(61)

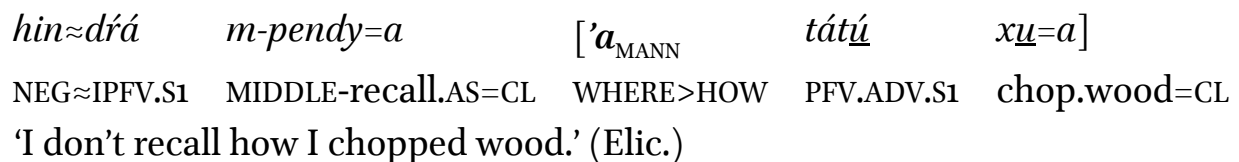

The argumental free relatives that I have illustrated so far are all definite. This means that they stand for a definite DP. This can be seen in an example like (62), where the appositional DP comes as an afterthought revealing the identity of the referent introduced by the free relative.
(62) ta nyut'y=a [to ti $\left.\quad x \underline{u}^{h} k y=a\right]$, PFV.IRR[S3] SS/go.in.AS=CL WHO IPFV.IRR[S3] wash.up.AS=CL
'The one who'll wash it up will come in, the old woman.' $\{\mathrm{Txt}\}$

Free relatives in Tilapa Otomi can equally be used to designate an indefinite referent; the indefinite reading is provided by the context and by predicates such as "search for", "have" or "exist". Such free relatives are called 'existential' in Caponigro (2003). Two textual examples are given in (63).

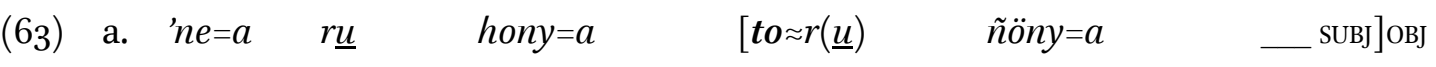 and $=\mathrm{CL} \quad \mathrm{HAB}[\mathrm{S} 3]$ look.for.AS=CL $\mathrm{WHO} \approx \mathrm{HAB}[\mathrm{S} 3]$ help.AS[O3] $=\mathrm{CL}$
'She looks for someone who's going to help her.' $\{$ Txt $\}$

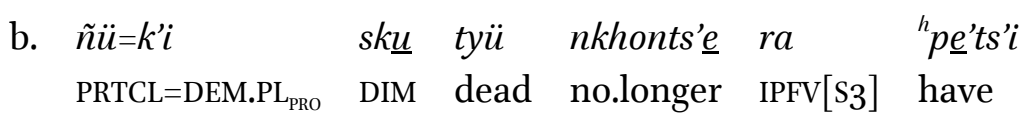

\begin{tabular}{|c|c|c|}
\hline$[t o \approx t a \ldots$ & $t o \approx t a$ & tómi \\
\hline $\mathrm{WHO} \approx \mathrm{PFV} . \mathrm{IRR}[\mathrm{S} 3]$ & WHO $\approx$ PFV.IRR[S3] & ss/wait[o3] \\
\hline
\end{tabular}

'Those dead people no longer have someone who may wait for them.' $\{$ Txt $\}$

The third and last type of free relative identified in Caponigro (2003) is called 'free-choice'. Freechoice headless RCs introduce a range of possible alternatives, all of them equally valid. In principle, the meaning of a simple free relative can be derived from the context, as for example in (64), which refers to all types of locations where the speaker could live, and not to a specific one.
(64) 'ne ['abw $\underline{u}$ gut $\underline{u}$
'mbwu] $\quad r a$
'mbwu $i$
ts'i $i^{h}$ pangu
and WHERE PFV.IRR.S1 live IPFV[S3] live CLF.PL mouse
'And wherever I may live there are mice.' $\{$ Txt $\}$ 
But more often than not, the interpretation of an open set of alternatives is conveyed by the use of the particle $x o$, which here is translated as 'EVER'. The same particle is also found in Acazulco Otomi, as reported in Hernández-Green (forthcoming). Examples are given in $(65-67)$ with different WH-words. In my corpus, when a free-choice free relative is an argument, it is commonly fronted.

(65) $[$ to $\approx x \boldsymbol{\varphi}$ ra nde ta $\quad m b \underline{a}=a]$ $\mathrm{WHO} \approx \mathrm{EVER} \quad \mathrm{IPFV}[\mathrm{S} 3] \quad$ want $\mathrm{PFV}$.IRR[S3] $\mathrm{ss} / \mathrm{sell}[\mathrm{O} 3]=\mathrm{CL}$

ba $\quad t a \quad m b \underline{a}$

EXHORT PFV.IRR[s3] Ss/sell[03]

'Whoever wants to sell it may sell it.' $\{$ Txt $\}$

(66)

$\begin{array}{lllll}{[t \boldsymbol{t} \approx x \boldsymbol{\varphi}} & x \approx t \underline{u} & h \underline{a} & a & \text { nana }] \\ \text { WHAT } \approx \mathrm{EVER} & \text { already } \approx \text { PFV.IRR.VEN>EXLOC[S3] } & \text { find } & \text { DEF.SG } & \text { woman }\end{array}$

$\begin{array}{ll}t \underline{u} & \text { 'uni } \\ \text { PFV.IRR.VEN>EXLOC[S3] } & \text { give.to.3.AS[O3] }\end{array}$

'Whatever the old lady finds, she gives it to him.' $\{$ Txt $\}$

(67) 'ne mba ['abw $\underline{u} \approx x \boldsymbol{o}$ grá nde] and [IMP]go WHERE $\approx$ EVER IPFV.IRR[S3] want

'And go wherever you want.' $\{$ Txt $\}$

In Tilapa Otomi, we also find syntactic clippings of free-choice free relatives that work as indefinite NPs of the type "whatever car" with the meaning "any car", like in (68).

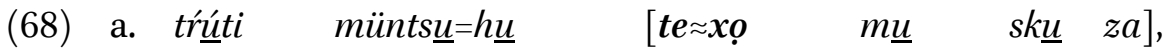

HAB.S1 gather.AS=PL.INCL WHAT $\approx$ EVER kind.of DIM tree

$\left[\boldsymbol{t e} \approx x \boldsymbol{o} \quad m \underline{u} \quad s k \underline{u} \quad t^{\prime} o\right]$

WHAT $\approx$ EVER kind.of DIM stick

'We're gathering any twig, any small stick.' $\{$ Txt $\}$

b. $\quad\left[t e \approx x \boldsymbol{Q} \quad n g \underline{a} t^{\prime} y=a\right]$ ti $\quad h e h=a$

WHAT $\approx$ EVER all.AS=CL PFV.IRR[S3] deliver.AS=CL

'They'll deliver anything.' (Lit. 'They'll deliver whatever all.') $\{\mathrm{Txt}\}$

Free-choice semantics applied to manner is never conveyed by a free relative. For this, there is a special construction involving the adverbial $p \underline{a n}=$ 'however' that occurs in the preverbal zone, as illustrated in (69).

(69) $p \underline{a n} \approx g i \quad k h a=t h o$ ya yi ${ }^{h} k o s a$

however $\approx$ IPFV.ADV[S3] do=DEL DEM.PL DEF.PL thing

'He does these things in no matter what sort of way.' $\{$ Txt $\}$ 


\subsubsection{Light-Headed Relative Clauses}

In the previous sections, we have seen three types of headless RCs in Tilapa Otomi which are also used in headed relative constructions, namely, asyndetic RCs; RCs introduced by a determiner as a relativizer; and RCs introduced by a WH-word. Headless RCs can either serve as arguments or adjuncts in the clause. There is another type of RC in Tilapa Otomi that is functionally equivalent to other types of headless RCs that function as arguments, but which is headed by a pronominal element. Following Citko (2004), I call such RCs 'light-headed' RCs. Examples in (70-71) illustrate this type. In (70), the RCs make reference to a human and in (71) to inanimate entities.

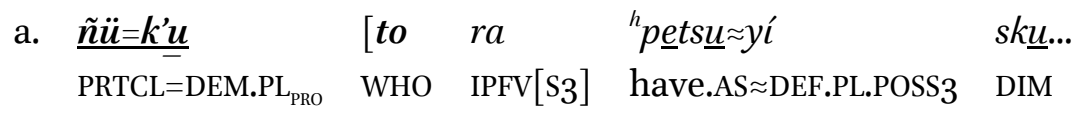

$$
\begin{array}{lllll}
y i & \text { sk } \underline{u} & k o s t u r a], & \text { bati } & \text { presenta }=k^{\prime} u \\
\text { DEF.PL.POSS3 } & \text { DIM } & \text { sewing } & \text { IMP.VEN }>\text { EXLOC } & \text { present[03]=there }
\end{array}
$$

'Those who have their embroideries, go and present them there!' $\{\mathrm{Txt}\}$

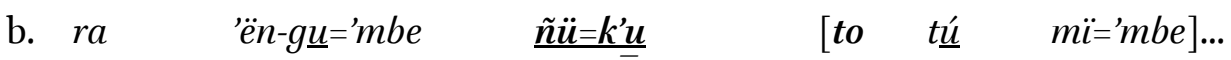

IPFV[S3] say-DAT1=PL.EXCL PRTCL=DEM.PL PRO $_{\text {PHO }} \quad$ PFV.S1 $\quad$ sit=PL.EXCL

'Those we sat with told us...' $\{$ Txt $\}$

$\begin{array}{lllllllll}\text { (71) a. } & \begin{array}{l}\text { mbw } \underline{u} \\ \text { then }\end{array} & g i & \tilde{n} \ddot{u}=w i & \underline{\tilde{n} \ddot{u}=y \underline{u}} & {[t a} & \text { thoh=kwa } & \text { 'a } & \text { muñü] } \\ & \text { PFV.IRR.S2 } & \text { see=PL } & \text { PRTCL=DEM.PL }{ }_{\mathrm{PRO}} & \text { PFV.IRR[S3] } & \text { pass=here } & \mathrm{P} & \text { above }\end{array}$

'Then you're going to see those that pass over here.' $\{$ Txt $\}$

b. 'uni=wi k' $\underline{u} \quad m \underline{u} \quad y o$

[IMP]give $=$ PL DEM.PL POSS10 $\quad$ dog

$\left.\begin{array}{lllll}\underline{\tilde{n} u ̈ u}=k^{\prime} \underline{u} & {[\text { gráti }} & \text { müntsi=gwa } & \text { 'a } & \text { mexa }\end{array}\right]$

'Give my dogs what you gather at the table here!' $\{$ Txt $\}$

The head of this type of RC is a pronominal phrase that is based on the presentational particle ñü, but we also encounter instances of the construction with the quantifier pronoun ngat'i 'all/everything', like in (72).

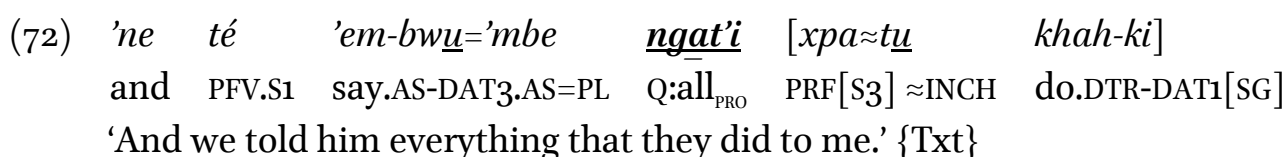

In this relative construction, the pronoun heads a RC as a light head. If the referent is human, like in (70), the RC must follow the relative pronoun strategy and be introduced by the wH-word to 'WHO', but if the referent is non-human, like in (71) or (72), an asyndetic RC is used instead. The cooccurrence of the relative pronoun and the pronominal in the structure in (70) strongly suggests 
that instances like (71-72) do indeed involve a light head and a RC and not a RC introduced by a relative pronoun.

We have seen that light heads in these relative constructions are pronominal elements. However, relative constructions with light heads exhibit a different distribution to the very pronominals on which they are based. When the pronominal phrases are used independently, they can only occur before the predicate, as seen in the examples in (73), which contrast with the ungrammaticality of those in (74). However, as we have seen in examples (7ob), (71) and (72), when the same proforms function as light heads, the relative construction in question can occur after the predicate as with any DP.

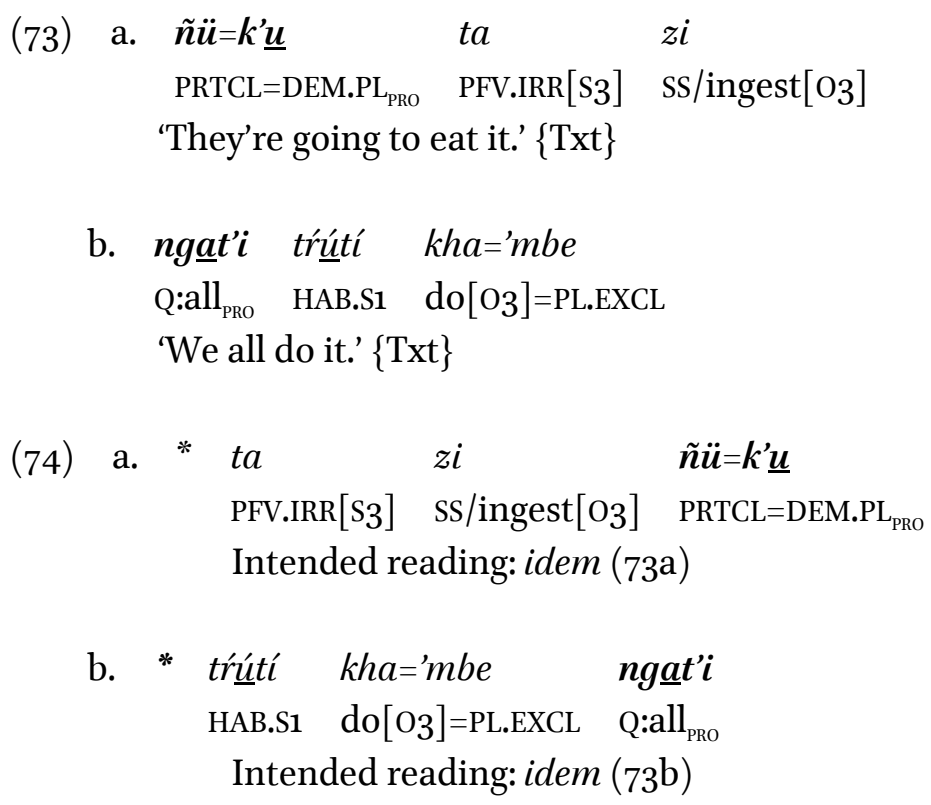

Light-headed relative constructions that stand for a locative adjunct have a different type of head, which I describe in the next section. In this connection, there are other instances of locative headless RCs in Tilapa Otomi that are puzzling. These are discussed in Section 8.3.4.2, where I propose that such headless RCs can only be interpreted as bearing an internal cleft to place the location in focus.

\subsubsection{Locative Light-Headed Relative Clauses}

While argumental light-headed RCs are headed by pronominal phrases, locative ones are headed by a pronominal enclitic that can be associated with the matrix predicate, like in $(75){ }^{13}$
(75) a. $m b \underline{a} \approx g \underline{u}$
${ }^{h} t y \ddot{u}=h \underline{u}=k^{\prime} u$
[IMP]SS/go.PL.INCL.AS $\approx$ PFV.IRR.S1 sow=PL.INCL=there

\footnotetext{
${ }^{13}$ The distal locative enclitic in the examples in (75) has a different surface realization because of prosodic parsing. In (75a), the enclitic appears unmodified at the end of a phonological phrase. In contrast, in $\left(75^{\mathrm{b}}\right)$ the speaker has chosen to integrate the free relative into the matrix clause by encliticizing the relative pronoun ' $a$ 'where', as the first free word of the clause, to the matrix predicate. Under this process, the right boundary of the predicate, here realized by the locative enclitic, undergoes morphotactic adjustment to serve as a phonological host for the relative pronoun.
} 


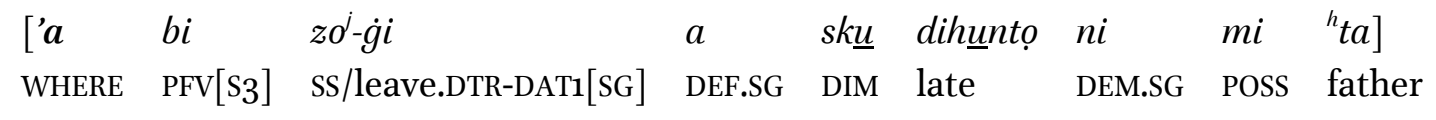
'Let's go over there where my late father left it (a cornfield) to me.' $\{\mathrm{Txt}\}$
$\begin{array}{ll}\text { b. } \quad \underline{\underline{u}} & { }^{h} t s \underline{t} \underline{u} \underline{u}=' m b e=' \underline{k w}\left[\approx \sim^{\prime} \boldsymbol{a}\right. \\ \text { PFV.S1 } & \text { arrive.AS=PL.EXCL }=\text { the }\end{array}$
ra 'mbwu ki
sku txango]
'We arrived there where the monkeys were.' $\{\mathrm{Txt}\}$
The

As in example (61) above, the locative to manner polysemy 'WHERE>HOW' is also found in lightheaded RCs. In such a construction, both the locative pronoun and the locative relative pronoun in the RC convey manner semantics, like in (76).
(76) bi $\quad n k h a=\underline{\prime} \underline{w}\left[\sim^{\prime} \boldsymbol{a}\right.$
tá $\quad x \underline{a} h-p \underline{u}=' m b e]$
$\mathrm{PFV}$ ss/be.so[s3] $=$ there $>$ so $\approx$ WHERE $>$ HOW
PFV.ADV.S1 teach.DTR-DAT3=PL.EXCL

'It was that way that we taught him.'

(Lit. 'It was so how we taught him.') $\{$ Txt $\}$

The locative enclitic in $\left(75^{-} 76\right)$ is the only pronominal enclitic that can serve as a light head in this type of relative construction. This is shown by the grammaticality contrast in examples like (77), where example $(77 \mathrm{a})$ is a repetition of $(7 \mathrm{Ob})$ above.
a. $r a \quad \dddot{e} n-g \underline{u}=' m b e \quad \underline{\tilde{n} \ddot{u}=k^{\prime} \underline{u}} \quad\left[\begin{array}{lll}\text { to } & \text { tú } \quad m \ddot{i}=' m b e] \ldots\end{array}\right.$
$\operatorname{IPFV}\left[\mathrm{S}_{3}\right] \quad$ say-DAT1.AS=PL.EXCL PRTCL=DEM.PL $\mathrm{PRO}_{\mathrm{PRO}} \quad$ WHO PFV.S1 $\quad$ sit=PL.EXCL
'Those ones we sat with told us...' $\{$ Txt $\}$

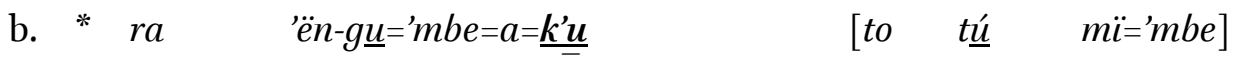
$\operatorname{IPFV}[\mathrm{S} 3] \quad$ say-DAT1.AS=PL.EXCL=CL=DEM.PL $L_{\mathrm{PRO}} \quad$ WHO PFV.S1 $\quad$ sit=PL.EXCL
Intended reading: idem (77a)

The ungrammaticality of $(77 \mathrm{~b})$ is intended to show that a pronominal enclitic that refers to an argument functioning as a light head is not permitted. Such pronominal enclitics are fine when used to refer to an argument of the predicate, like in $(78 \mathrm{a})$, where the pronominal enclitic refers to the subject. Example $(77 \mathrm{~b})$ can only be grammatical if the free relative is interpreted as an appositional headless RC, that is, a RC which elaborates further on the reference of the pronominal so that the right referent can be identified, like in $(78 \mathrm{~b})$.
a. $\quad r a \quad \dddot{e} n-g \underline{u}=' m b e=a=k^{\prime} \underline{u}$
$\operatorname{IPFV}[\mathrm{S} 3] \quad$ say-DAT1.AS=PL.EXCL $=\mathrm{CL}=$ DEM.PL $\mathrm{PRO}_{\text {PRO }}$
'Those [they] told us.'

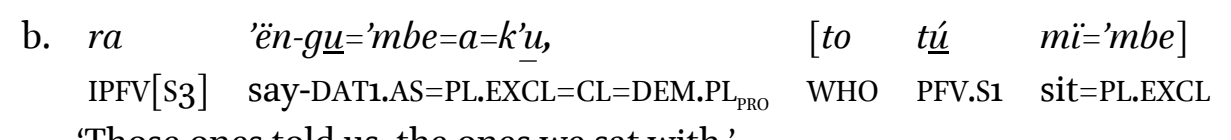

'Those ones told us, the ones we sat with.'

8.3.4.2 Some Puzzling Instances of Locative Headless Relative Clauses 
We have seen so far two different types of headless relative constructions with locative meaning: one that involves a free relative with a locative relative pronoun ' $a$ 'WHERE', like in (79a); and another that involves a light-headed RC with a locative light head and a RC bearing the same locative pronoun, like in (75a), repeated here as (79b).

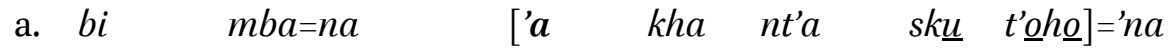

$$
\begin{aligned}
& \mathrm{PFV}[\mathrm{S3}] \quad \mathrm{SS} / \mathrm{go}=\mathrm{DEM}_{\mathrm{SG}} \text { PRo WHERE exist INDF.SG DIM mountain=REP }
\end{aligned}
$$

'And they say that this one went where there was a hill.' $\{\mathrm{Txt}\}$

b. $\quad m b \underline{a} \approx g \underline{u}$

${ }^{h} t y \ddot{u}=h \underline{u}=\underline{k} \dot{u}$

[IMP]SS/go.PL.INCL.AS $\approx$ PFV.IRR.S1

sow $=$ PL.INCL=there

\begin{tabular}{|c|c|c|c|c|c|c|c|}
\hline$[' a$ & $b i$ & $z o^{\prime}-\dot{g} i$ & $a$ & sk $\underline{u}$ & dihunto & $n i$ & $m i$ \\
\hline WHERE & $\mathrm{PFV}\left[\mathrm{S}_{3}\right]$ & SS/leave.DTR-DAT1[SG] & DEF.SG & DIM & late & DEM.SG & POSS1운 \\
\hline
\end{tabular}

In natural discourse, speakers of Tilapa Otomi also use headless relative constructions that involve a RC with the locative relative pronoun 'abw $\underline{u}$ 'WHERE' hosting a locative pronominal enclitic. The examples in (8o) illustrate this possibility. Note that $(8 \mathrm{ob})$ is an instance of a free-choice free relative.

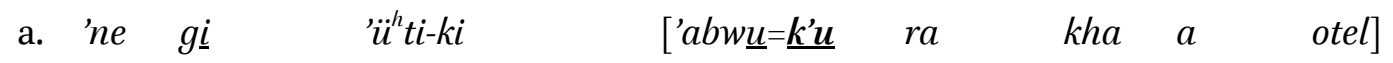

$$
\begin{aligned}
& \text { and PFV.IRR.S2 show.DTR-O1[SG] WHERE=there IPFV[S3] exist DEF.SG hotel } \\
& \text { 'And show me (there) where the hotel is.' }\{\text { Txt }\} \\
& \text { b. pus gu } \underline{u} \quad m \underline{e}=' m b e=a \\
& \text { ah.well PFV.IRR.S1 Ss/go.DU=PL.EXCL=CL } \\
& \text { ['abw } \left.\underline{u}=\underline{\prime} \underline{u} \quad x \underline{o} \approx t i \quad t s^{\prime} i x-k \underline{u}=' m b e=a\right] \\
& \text { WHERE=there EVER } \approx \text { PFV.IRR[3] PASS/carry.animate.AS-O1=PL.EXCL=CL } \\
& \text { 'Ah well, we'll go (there) wherever they take us.' }\{\text { Txt }\}
\end{aligned}
$$

The construction in (8o) is puzzling and calls for an explanation. Although it may seem so, the structure in (8o) cannot be interpreted as exhibiting a retention relativization strategy with an internal light head, mainly because of the co-occurrence of the locative relative pronoun 'abw $\underline{u}$ 'WHERE'. Given that such an account is not appealing, one might wonder what type of construction the examples in (8o) instantiate. It is true that an example like (8oa) can be alternatively rendered like (81) with exactly the same meaning.
(81) 'ne $g \underline{i}$
and

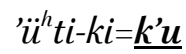
['abw $\underline{u}$ ra
kha $\quad$ a otel $]$ idem (79a)

If both (8oa) and (81) have the same semantics, one could argue that the construction in (8o) obtains after a morphotactic shift of the locative pronoun with respect to its phonological and 
syntactic host, e.g. from $[\mathrm{V}=\mathrm{LOC}[\mathrm{WH} . .]$.$] to [\mathrm{V}[\mathrm{WH}=\mathrm{LOC} . .]$.$] , which results in a surface structure$ that appears to reflect an internal light head. Such an analysis would be tenable, if it were not for instances exhibiting double marking, like in $(82) \cdot{ }^{14}$

\begin{tabular}{|c|c|c|}
\hline$m b \underline{a h} \underline{a}$ & $g \underline{u}$ & ${ }^{h} p \ddot{o}=h \underline{u}=\underline{k} \boldsymbol{w}=a$ \\
\hline SS/go.PL.INCL & PFV.IRR.S1 & know.AS=PL.INCL=there $=C L$ \\
\hline$=k^{\prime} u$ & hin $\approx g r a$ & $\left.{ }^{h} p \ddot{o}=h \underline{u}\right]$ \\
\hline סחנ & NEG $\approx$ IPFV.I & RR.S1 know.AS=PL.INCL \\
\hline
\end{tabular}

'Let's go and visit those places where we have never been to.'

(Lit. 'Let's go to know there where we don't know.') \{Txt\}

The fact that the locative pronoun occurs twice in the same construction suggests that it has a different function each time it is used. If we accept that the first instance is a canonical light head, just like in (81), then we just need to account for the instance within the RC. I propose that the locative pronoun inside the $\mathrm{RC}$ in constructions like (80) and (82) realizes a copular construction, so that these examples can be interpreted as instances where the location is presented in focus. Evidence for this analysis comes from the syntax of interrogatives.

Most interrogative clauses in Tilapa Otomi are based on clefts, and clefts are based on the copular construction (see Palancar 2018a for more details). The copular construction in Tilapa Otomi may involve just a copula, like in the question in (21), repeated here as (83a), or it may also involve a pronominal enclitic at the right edge of the clause that cross-references the subject in focus (see Palancar 2019b), like in (27), repeated here as (83b).

$$
\begin{array}{lllll}
\text { a. } & \text { 'abwu } & \text { ke } & \text { gú } & \text { phunts'i? } \\
\text { WHERE } & \operatorname{COP}\left[\mathrm{S}_{0} 3\right] & \text { PFV.S2 } & \text { fall }
\end{array}
$$

'Where is it that you fell?' $\{\mathrm{Txt}\}$

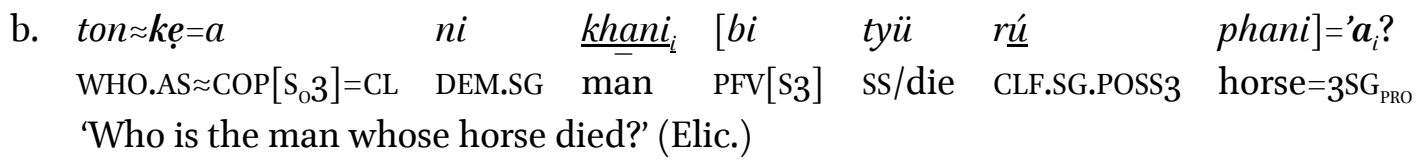

When asking about a location, the cleft construction in (83a) can be used, or the cleft construction in (84), where the copular cross-referencing enclitic is pied-piped to the front of the clause and is hosted on the WH-word.

(84) ' $a b w \underline{u}_{i}=' k u_{i} \quad a \quad$ di hñ̈ñ̈̈? WHERE=there DEF.SG POSS2 village

'Where is your village?' $\{\mathrm{Txt}\}$

(Lit. 'Where is there your village?')

I propose that the optimal way to interpret the structures in $(80)$ and $(82)$ is to think of them as instantiating RCs bearing the relative pronoun 'abwu 'WHERE' that further display an internal cleft,

\footnotetext{
${ }^{14}$ The enclitic $=a$ associated with the matrix predicate after the locative pronoun has no bearing on the syntax of the construction, but simply indicates the prosodic boundary of a phonological phrase.
} 
in the same fashion as (84). In this light, the difference between the constructions in (79) and those in (8o) and (82) is one based on information structure, so that the locations referred to in $(80)$ and $(82)$ are presented as being in focus. In such a way, examples (8oa), (8ob) and (82) should be literally translated as "show me where it is that the hotel is"; "we'll go wherever it is that they take us"; and "let's go to know there where it is that we don't know", respectively.

\subsection{Summary of the Proposal}

In this chapter, I have described RCs in Tilapa Otomi. Methodologically, I have distinguished two main types of relative constructions: those that are headed by a full nominal and modify that domain nominal by restricting its reference, which I have treated as 'headed relative constructions'; and those that function as clausal arguments or adjuncts of a matrix predicate, which I treat as 'headless relative constructions'. I have first concentrated on the three types of RCs that can function as modifiers in headed relative constructions: (i) a type that is asyndetic; (ii) another that is introduced by a determiner (that I have argued is a relativizer which agrees with the head of the DP embedding the domain nominal); and (iii) a third type that uses a relative pronoun strategy, only available to two relative pronouns derived from wH-words: to 'WHO' and 'abw $\underline{u}$ 'WHERE'.

I have shown that the types of RCs which employ a gap relativization strategy are used to relativize a wide range of functions in the relativization hierarchy, while those based on the relative pronouns WHO and WHERE are more restricted and have their own idiosyncrasies. The locative relative pronoun strategy based on 'abwu 'WHERE' is the only possible way to relativize a locative adjunct. The RC based on to 'WHO' can only relativize a human subject and a human possessor, but I have shown that it can also be used to relativize a comitative participant because in Tilapa Otomi, just like in other Otomian languages, comitatives are encoded as second subjects in a split conjunction construction where the matrix predicate agrees in number with both subject and comitative.

The three types of RCs can also be used in headless relative constructions. The one based on a relative pronoun strategy gives rise to free relatives that are used to relativize a wider range of functions in the relativization hierarchy (including subject and comitative, object, instrument, temporal, locative and manner). Free relatives can be definite or maximal, indefinite or existential, or free-choice (Caponigro, 2003). I have also argued that the language has a fourth type of RC used in a headless relative construction that involves a pronoun as a light head.

\section{Acknowledgements}

My main language consultant, Mrs. Petra Cruz Gutiérrez-Mora, died during the process of publishing this book. This chapter is dedicated to her memory. This chapter benefited from the support of the 2016-2018 CNRS-PICS research project "Mesoamerica and the syntax of the relative clause". I want to thank Roberto Zavala and Claudine Chamoreau for their help in improving previous drafts with their comments and suggestions. I presented an early version of this work at a workshop on relative clauses coordinated by Judith Aissen at CIESAS-Sureste in 2016. I am grateful to all participants for the discussions and observations made. I am also grateful to Timothy Feist 
for proofreading the English language for me. All errors and deficiencies remain my own responsibility.

\section{BIBLIOGRAPHY}

Aissen, Judith L. 1989. Agreement controllers and Tzotzil comitatives, Language 65: 518-536.

Caponigro, Ivano. 2003. Free not to ask: On the semantics of free relatives and wh-word crosslinguistically. PhD Thesis. University of California at Los Angeles.

- 2021. Introducing Headless Relative Clauses and the findings from Mesoamerican languages. In Ivano Caponigro, Harold Torrence \& Roberto Zavala Maldonado (eds.), Headless Relative Clauses in the Mesoamerican Languages, 1-57. Oxford: Oxford University Press.

Citko, Barbara. 2004. On headed, headless, and light headed relatives, Natural Language and Linguistic Theory 22: 95-126.

Hernández-Green, Néstor. 2016. Registration versus applicative constructions in Acazulco Otomi, International Journal of American Linguistics 82(3): 353-383.

Hernández-Green, Nestor. Forthcoming. Headless relative clauses in Acazulco Otomi. In Ivano Caponigro, Harold Torrence \& Roberto Zavala (eds.).

Keenan, Edward \& Comrie, Bernard. 1977. Noun phrase accessibility and universal grammar, Linguistic Inquiry 8 (1): 63-99.

Lehmann, Christian. 1986. On the typology of relative clauses, Linguistics 24: 663-68o.

Palancar, Enrique L. 2012. A typology of split conjunction, Linguistic Typology 16: 265-320 . 2018a. Clefts in Otomi: Extended uses of the copular construction, International Journal of American Linguistics 84(1): 93-145.

. 2018b. Subjects and focus in clefts: The case of Tilapa Otomi. In Evangelia Adamou, Katharina Haude and Martine Vanhove (eds.), Information structure in lesser-described languages: Studies in prosody and syntax, [SLCS 199], 245-264. Amsterdam: John Benjamins

Palancar, Enrique L. \& Leonardo Carranza Martínez. 2021. Headless relative clauses in Matlatzinca. In Ivano Caponigro, Harold Torrence \& Roberto Zavala (eds.), Headless relative clauses in Mesoamerican languages, 145-176. New York: Oxford University Press.

Polian, Gilles \& Judith Aissen. 2021. Headless relative clauses in Tseltalan. In Ivano Caponigro, Harold Torrence \& Roberto Zavala Maldonado (eds.), Headless Relative Clauses in the Mesoamerican Languages, 403-443. Oxford: Oxford University Press.

Schwartz, Linda. 1985. Plural pronouns, coordination, and inclusion. In Nancy Stenson (ed.), Papers from the Tenth Minnesota Regional Conference on Language and Linguistics, 152-184. Minneapolis: Department of Linguistics, University of Minnesota. . 1988. Conditions for verb-coded coordination. In Michael Hammond, Edith A. Moravcsik \& Jessica R. Wirth (eds.), Studies in syntactic typology, 53-73. Amsterdam: Benjamins.

Smith Stark, Thomas C. 1988. Pied-piping con inversion en preguntas parciales. México: COLMEX. ms. 